\title{
Users' Music Information Needs and Behaviors: Design Implications for Music Information Retrieval Systems
}

\author{
Jin Ha Lee (corresponding author) \\ Information School, University of Washington \\ Mary Gates Hall, Suite 370, Seattle WA 98195 \\ Phone: 206.685.0153 \\ Email: jinhalee@uw.edu \\ Hyerim Cho \\ Information School, University of Washington \\ Mary Gates Hall, Suite 370, Seattle WA 98195 \\ Phone: 206.685.0153 \\ Email: chohr113@uw.edu \\ Yea-Seul Kim \\ Human Centered Design \& Engineering, University of Washington \\ Sieg Hall, Room 423, Seattle WA 98195 \\ Phone: 206.543.2567 \\ Email: yeaseul1@uw.edu
}

\begin{abstract}
User studies in the music information retrieval (MIR) domain tend to be exploratory and qualitative in nature, involving a small number of users, which makes it difficult to derive broader implications for system design. In order to fill this gap, we conducted a large-scale user survey questioning various aspects of people's music information needs and behaviors. In particular, we investigate if general music users' needs and behaviors have significantly changed over time by comparing our current survey result with a similar survey conducted in 2004. In this paper, we present the key findings from the survey data and discuss 4 emergent themes-(a) the shift in access and use of personal music collections; (b) the growing need for tools to support collaborative music seeking, listening, and sharing; (c) the importance of "visual" music experiences; and (d) the need for ontologies for providing rich contextual information. We conclude by making specific recommendations for improving the design of MIR systems and services.
\end{abstract}

\section{Introduction}

The rapid development of tools and technologies for music use, storage, and distribution in recent years has revolutionized the way people experience music. The availability, accessibility, and portability of music have been transformed in ways hardly imaginable just a few decades ago. Over the past 2 decades alone, people have seen portable music listening devices change from cassette, to $\mathrm{CD}$, to iPod, to smartphone. The pace of this change is not slowing down; mobile phone use continues to rise, with 141 million Americans reporting 
the use of smartphones (comScore, 2013), and, as of May 2013, over half of smartphone users report listening to music on their phones (Brenner, 2013). Digital music sales continue to grow, with more than 117 million albums and with 1.34 billion single tracks purchased digitally in the US in 2012, accounting for more than 55\% of all music sales (Nielsen, 2013). Cloud music services are now available to users who choose to upload their music to the cloud rather than keeping a physical music collection or digital music files on home devices. Other users give up ownership entirely in favor of streaming media such as Spotify ${ }^{1}$ and Pandora ${ }^{2}$ (Lee \& Price, in press).

In this fast-changing domain, understanding users' current music information needs and behaviors is crucial for developing successful music information retrieval (MIR) systems and services. The importance of empirical user studies has been noted multiple times in the MIR literature (e.g., Futrelle \& Downie, 2002; Cunningham, 2003; Downie, Byrd, \& Crawford, 2009; Lee, 2010a), and the number of user studies has gradually been increasing. However, many of these user studies are largely exploratory in nature, and tend to investigate a small group of users employing qualitative methods such as ethnographic observation or in-depth interviews (Lee \& Cunningham, 2013; Weigl \& Guastavino, 2011). Although they can provide rich information about users, the data obtained may be highly personal and not representative of users at large and therefore it is difficult to derive broader implications for system design. Only a small number of studies in the MIR domain investigate users' music needs, use patterns, preferences, and behaviors through large-scale surveys (e.g., Ellis, Whitman, Berenzweig, \& Lawrence, 2002; Lee \& Downie, 2004; Lesaffre et al., 2008; Barrington, Oda, \& Lanckriet, 2009; Lai \& Chan, 2010; Brinegar \& Capra, 2011). Furthermore, due to the constant changes in the ways people listen to, store, and share music, it is essential to regularly conduct user studies in order to stay informed about current needs and behavior.

We conducted a large-scale user survey questioning various aspects of people's music information needs and behaviors. This work is an extension of previous survey research conducted in 2004 by the first author (Lee \& Downie, 2004). The findings obtained from this research will not only help improve our understanding of music users for better MIR system design, but also allow us to comprehend how the needs and behaviors of music users have changed since 2004.

\section{Relevant Work}

In the general field of information behavior, a number of well-developed theories and models exist. Prime examples are Wilson's information behavior model $(1981,1997)$, Dervin's sense-making theory (1983), Ellis's model of information behavior (1989), Kuhlthau's information search process (Kuhlthau, 1993), Savolainen's everyday life information seeking (ELIS) model (1995), Krikelas's (1983) and Leckie, Pettigrew, and Sylvain's (1996) models simulating the process of information behavior. However, these theories and models have limited applicability to information behavior in contexts such as MIR, where deriving specific design implications from users' behavior is the primary focus (Lee, 2010a).

User studies in MIR focus on investigating distinctive issues that emerge in users' music information-seeking, use, storage, and sharing activities. The beginning of the substantial growth of MIR user studies can be traced back to the early 2000s (Lee \& Cunningham, 2013). These studies investigated various aspects related to users' experience and 
interaction with music: users' information needs; music use and organization; search and browse behaviors; and music perceptions, preferences, and opinions (Lee \& Cunningham, 2013; Weigl \& Guastavino, 2011). A variety of research methods were employed-studies employing semistructured interviews (e.g., Taheri-Panah \& MacFarlane, 2004; Laplante \& Downie, 2006; Inskip, Butterworth, \& MacFarlane, 2008), ethnographic observations (e.g., Cunningham, Reeves, \& Britland, 2003; Cunningham, Jones, \& Jones, 2004), diary study (e.g., Cunningham, Bainbridge, \& McKay, 2007), and controlled experiment (e.g., Pauws \& Eggen, 2002) tend to involve a small number of users, and often focus on specific groups of music users based on their age or profession. Studies employing a survey method (e.g., Downie, 1994; Lee \& Downie, 2004) or content analysis of user search log, questions, and tags (e.g., Itoh, 2000; McPherson \& Bainbridge, 2001; Bainbridge, Cunningham, \& Downie, 2003; Sordo, Celma, Blech, \& Guaus, 2008) tend to provide a quantitative analysis on more substantial amounts of user data obtained from a larger number of subjects, collected online or through crowdsourcing.

Among these different types of user studies, we extensively searched for large-scale MIR user studies (involving more than 100 subjects). Several focus on collecting user data on specific aspects of MIR such as music similarity or mood judgments. Ellis et al. (2002) collected over 6,200 user responses on artist similarity through a web-based game "MusicSeer" and found that subjective artist similarities do vary among users. Barrington et al. (2009) conducted a playlist evaluation experiment with 185 subjects and confirmed that Apple iTunes Genius's collaborative filtering approach performed well on their pop music test collection, and users being able to see the metadata of the songs significantly affected how the playlist is evaluated. Studies by Lee (2010b), Mandel, Eck, and Bengio (2010), Urbano, Morato, Marrero, and Martin (2010), and Lee, Hill, and Work (2012) employed crowdsourcing and collected somewhere between 50 to 2,500 user responses on music mood and similarity, revealing issues in collecting users' judgments as well as demonstrating the viability of using crowdsourcing for generating ground truth for multiple evaluation tasks.

Some large-scale user studies focused on investigating particular user groups such as university music library users (Lai \& Chan, 2010) or visitors to a music museum (Maguire, Motson, Wilson, \& Wolfe, 2005). Lai and Chan (2010) learned about participants' preference for certain materials such as scores and multimedia over other types of library materials. Maguire et al. (2005) discovered that improving the system's user interface was the most important suggestion made by the museum visitors for changes in their digital collection, highlighting the importance of the design of the system. Other large-scale MIR user studies dealt with broader topics and involved more general user populations. Lee and Downie (2004) conducted a multi-group online survey, aiming to provide an empirical basis for MIR system development. They found that people display "public information seeking" behaviors by making use of collective knowledge and/or opinions of others about music such as reviews, ratings, and recommendations in their music information seeking. Also, the study participants expressed needs for contextual metadata (e.g., associated use) in addition to traditional bibliographic metadata. Lesaffre et al. (2008) collected 663 survey responses to understand the influence of demographics and musical background on how people describe music's semantic qualities. They discovered that gender, age, musical expertise, active musicianship, and broadness of taste and familiarity with the music influenced people's semantic description of music. Brinegar and Capra (2011) also surveyed 184 respondents to investigate how users manage music across multiple devices, and found that users synchronized their music across multiple devices frequently by physically 
transferring music using external hard drives and optical media, and although $75 \%$ of respondents kept some form of backup of their digital music, their methods were ad-hoc.

Other large-scale user studies analyze a substantial amount of existing user data collected from different information sources, rather than directly collecting them from users.

Bainbridge et al. (2003) and Lee (2010a) analyzed the questions and answers posted to the music category of Google's "ask an expert" service, Google Answers. They analyzed somewhere between 500 to 2,000 queries using a grounded theory approach to discover which features would be useful for performing an MIR task. Bainbridge et al. (2003) found that the need for bibliographic information was most dominant (appeared in $81.3 \%$ of questions), and among bibliographic information needs, information about performers (58.8\%) was most important. Lee (2010a) also confirmed the importance of bibliographic information and added that although a large number of features were used in people's questions searching for music, a few key features were used much more frequently: person name, title, date, genre, role, lyric, and place. Also, despite various syntactic and semantic errors in users' questions, they were still successful in eliciting correct answers in many cases. Sordo et al. (2008) analyzed over 90,000 user tags collected from Last.fm ${ }^{3}$ and compared those to the genre terms collected from MP3.com and found that swith some genres it was difficult to get a consensus between the experts and the "wisdom of crowds."

Collectively, these MIR user studies have helped improve our general understanding of various aspects of people's use of music information systems, including: the different types of metadata that are most significant and potentially useful, users' music search behavior, problems in how users manage their collections, and the value of user data (e.g., ratings and judgments) for the purposes of system development and evaluation. This study aims to add further insights into current music users' needs and behaviors, and make specific recommendations for designing future music information systems and services. In particular, we investigate whether users' needs and behaviors have changed significantly over time for general music users.

\section{Study Design}

The survey was implemented online using LimeSurvey, an open-source survey application. The survey instrument contained a total of 23 questions asking about why, where, how, and how often users seek and obtain various kinds of music information; who they ask for help; how they use music information; which music-related websites/apps they use; and how they manage and organize their music collection.

Most of the questions were adopted from a survey conducted in 2004 by Lee and Downie (2004) to allow for a comparative analysis of responses. Four new questions were added to the new survey regarding how users manage physical and digital music collections, which devices they use to listen to music, and also an open-ended question seeking additional comments about the survey. Response options for some questions were modified in order to reflect new developments in tools and technologies used for interacting with music (e.g., cloud music services, music identification services, social media). We also collected demographic information, and asked questions about respondents' musical abilities (e.g., singing, playing an instrument, reading sheet music) and if they have music-related professions. Several follow-up questions were asked based on how users answered the main questions. The survey instrument is summarized in Table 1 (see Appendix for the full questionnaire). 
Table 1. Summary of survey instrument

\begin{tabular}{|c|c|}
\hline Question Groups & Questions \\
\hline \multirow[t]{4}{*}{ Demographic information } & Gender \\
\hline & Age \\
\hline & Race/Ethnicity \\
\hline & $\begin{array}{l}\text { Do you have a music-related profession? } \\
\text { If yes: Type of music-related profession }\end{array}$ \\
\hline \multirow{6}{*}{$\begin{array}{l}\text { User's musical taste, } \\
\text { literacy, and ability }\end{array}$} & Preferred genres (up to 5) \\
\hline & Level of interest in music \\
\hline & Ability to read sheet music \\
\hline & Ability to sing \\
\hline & $\begin{array}{l}\text { Ability to play a musical instrument } \\
\text { If yes: Type of instrument and ability to replicate a melody }\end{array}$ \\
\hline & Devices for listening music \\
\hline \multirow[t]{3}{*}{ Information needs } & Frequency of seeking 11 different formats of music information \\
\hline & Frequency of music search conducted for 16 reasons \\
\hline & Likelihood of seeking 15 types of music information \\
\hline \multirow[t]{6}{*}{$\begin{array}{l}\text { Information seeking } \\
\text { behaviors }\end{array}$} & $\begin{array}{l}\text { Do you search for music information online? } \\
\text { If yes: Frequency of } 12 \text { online music-related activities }\end{array}$ \\
\hline & Favorite music-related websites/apps and reasons \\
\hline & Frequency of visiting 4 physical places for seeking music information \\
\hline & $\begin{array}{l}\text { Frequency of consulting } 8 \text { types of people/services for seeking music } \\
\text { information }\end{array}$ \\
\hline & Frequency of music search triggered by 10 sources \\
\hline & Likelihood of using 28 search/browse options \\
\hline \multirow{2}{*}{$\begin{array}{l}\text { Organization and } \\
\text { management of music } \\
\text { collection }\end{array}$} & $\begin{array}{l}\text { Do you manage a physical music collection? } \\
\text { If yes: Size of collection and organization methods }\end{array}$ \\
\hline & $\begin{array}{l}\text { Do you manage a digital music collection? } \\
\text { If yes: Size of collection, organization methods, and primary } \\
\text { management methods }\end{array}$ \\
\hline
\end{tabular}

For both surveys, participants were 18 years or older who listen to music and/or seek music information for any reason. For the new survey, invitations were distributed on multiple online venues including various mailing lists for students, faculty, and staff at University of Washington as well as other music-related online communities such as MLA-L (the Music Library Association Discussion List) and ISMIR (International Society for Music Information Retrieval). We also recruited participants through social media networks such as Facebook, Twitter, and Google Plus. Many users on social media also chose to share or forward invitation messages to their friends and other communities. All procedures were approved by the University of Washington's Human Subjects Division. Participants were offered an opportunity to enter in a raffle to win a total of $\$ 200$ worth of Amazon gift cards. The survey was active for approximately 2 months (December 15, 2011 to Feb 16, 2012). A total of 755 respondents participated in the survey, and of those, 524 completed the survey. Upon reviewing the responses, 21 were removed due to being less than $50 \%$ complete, resulting in a total of 503 usable responses.

For the 2004 survey (Lee \& Downie, 2004), the authors sampled two population groups: (a) Group I: University of Illinois at Urbana-Champaign campus community and (b) Group II: 
the general public over 18 years old who were recruited online through various musicrelated forums and mailing lists. The survey was active for approximately 1 month (April 9, 2004 to April 30, 2004 for Group I, and to May 2, 2004 for Group II). Between Group 1 and Group II, a total of 768 responses were collected. A total of 738 usable responses were left, after removing 30 incomplete responses.

For the Group I population in the 2004 survey, the authors sed a stratified random sampling approach based on gender and academic/professional status (Lee \& Downie, 2004). The respondents from the Group II population, on the other hand, were recruited relying on convenience sampling. More detailed information on their study design and sampling approach can be found in Lee and Downie (2004). For the new survey, we also relied on convenience sampling, as we were unable to obtain a list of email addresses of the University of Washington campus population for survey purposes, due to privacy concerns. We hoped to compensate collecting a substantial number of responses; however, we note this limitation to remind readers to be mindful as we make comparisons of the two survey results.

In this paper, we will be discussing the survey results with regard to: (a) music information needs, (b) music information-seeking behaviors, and (c) behaviors surrounding music organization and collection. Here, we analyze and show how the results from the 2004 and 2012 surveys compare for general users who do not have music-related professions. This is due to the findings from previous small-scale qualitative studies suggesting music experts' information needs and behaviors may differ from those of general users (e.g., Lee \& Moon, 2006; Inskip et al., 2008; Barthet \& Dixon, 2011). After removing the data of participants who responded that they had a music-related profession, we had 595 applicable responses from the 2004 survey and 251 from the new survey. The results from users with musicprofessions will be reported in a separate article.

In the following section, we present our key findings supported by relevant descriptive statistics for each topic. We also performed a chi-square goodness-of-fit test in order to determine whether the discrepancies between distributions in the 2004 and 2012 surveys are statistically significant. Despite the limitations of using chi-square statistics with convenience sampling, we still refer to them to further support our analysis. It is not uncommon to use inferential statistics on a sample that was not randomly collected, but in order to have more confidence in the results, several replication studies should be performed to further verify and confirm the results (McHugh, 2013). Having multiple similar studies, involving different user groups, will also help overcome the limitations of using a convenience sampling method by supporting or refuting our findings.

\section{Data and Discussion}

\section{Demographic Information}

The average age of respondents was 38.1 ( $\mathrm{SD}=10.7$ ) for the previous survey, and 35.2 (SD $=11.3$ ) for the new survey. In the previous study, $50.6 \%$ were male, $46.7 \%$ were female, and $2.7 \%$ selected "other" or did not specify their gender. In the new survey, $59.8 \%$ of respondents were female, $36.2 \%$ were male, and $4 \%$ of respondents selected "other" or did not answer. Seventy-two percent of respondents in the previous survey and $64 \%$ of respondents in the new survey described themselves as White or Caucasian, followed by $16.0 \%$ (in 2004) and 23.1\% (in 2012) who identified as Asian, respectively. 
We also asked several questions in order to gauge users' music literacy and musical abilities. Forty-three percent of respondents from the previous survey and $29.5 \%$ from the new survey said they can read sheet music "fairly well" to "very well." Approximately one quarter $(23.2 \%)$ of respondents from the previous survey and $16.3 \%$ of the respondents from the new survey said they can sing "fairly well" or "very well." Almost half of the respondents from both studies said they can play some kind of musical instrument (49.4\% in 2004, 50.2\% in 2012), and 18.3\% (in 2004) and 9.6\% (in 2012) can replicate a melody on a piano after they heard it without difficulties.

In response to the question asking users to characterize their level of interest in and interaction with music, $74.5 \%$ of respondents from the previous survey and $66.5 \%$ from the new survey answered that they were avid listeners, and 21.3\% (in 2004) and 35.5\% (in 2012) of respondents from each study said that they were casual listeners. Forty percent (in 2004 ) and $22.3 \%$ (in 2012) replied they were musically passionate (i.e., I really like music and it is a big part of my life), and 15.6\% (in 2004) and 24.7\% (in 2012) answered they were musically curious (i.e., I enjoy music, but I am not too crazy about it). Eleven percent (in 2004) and 2\% (in 2012) of respondents said they were avid performers playing musical instruments or singing regularly, and 23.7\% (in 2004) and 19.1\% (in 2012) replied that they were casual performers who play musical instruments or sing occasionally. The respondents were allowed to select multiple responses to this question.

We also asked participants to identify and rank their favorite music genre in order to get a better understanding of their tastes. The top-ranked music genres among the previous study population were "Rock (18.0\%)" and "Alternative (12.6\%)," compared to "Alternative (36.2\%)," and "Blues (19.6\%)" from the new survey. It will be worthwhile to investigate the association between the trends of preferred musical genres and sociocultural (or even technological) phenomena in future studies.

In the new survey, we asked additional questions about the devices people use when listening to music. These questions were not included in the old survey. Most of the respondents (98\%) selected computer, more so than iPod/mp3 player (56.6\%) or stereo $(50.2 \%)$. Phones were also used by $73.3 \%$ of respondents, which is higher than the results reported in Brenner (2013) that about half of smartphone users report listening to music with their phones.

Overall, the data show that the respondents from both surveys consist of a mix of avid and casual listeners with a range of musical literacy and abilities. Respondents were more confident about playing instruments than singing or reading sheet music. Additionally, for both surveys, White/Caucasian users in their 20 s or 30 s are predominantly represented in the samples. Although the findings from this survey do provide a bigger picture of users' needs and behaviors, we also note the possible limitations on the generalizability of the findings to a diverse user population due to these reasons.

\section{Music Information Needs}

\section{Types and formats of music-related materials sought}

Table 2 shows the summary of music-related materials sought by respondents. Similar to what Lee and Downie (2004) found, seeking music as an auditory experience and for 
entertainment is still primarily important in the new survey (also noted in Table 3). We observed a substantial and statistically significant increase in the proportions of respondents seeking digital music files and a decrease in physical recordings and scores. In both surveys, printed materials such as journal articles, books, or magazines were sought by smaller proportions of respondents. Of the different types of music-related textual information, "music/entertainment news" was the most commonly sought item in both surveys, again highlighting the use of music for entertainment. Although approximately half of the respondents said they could play some kind of musical instrument, music scores were not sought by many respondents. Search for textual information and scores was also much less frequently conducted, evidenced by the high proportion of responses that selected "once a month or less" (Figure 1). Respondents mentioned lyrics, concert dates and tour schedule, music review, information about instruments, discography, artist biography, etc. as other types of music-related materials they seek.

Table 2. Responses to "How often do you search for the following items (both online and offline)?" (Q4)

\begin{tabular}{|c|c|c|c|c|c|c|c|}
\hline \multirow[b]{2}{*}{ Type } & $\begin{array}{l}\text { Survey } \\
\text { version }\end{array}$ & Positive $^{4}$ & Negative & Valid N & $\begin{array}{c}\text { Gap } \\
\text { (new-old) }\end{array}$ & $X^{2}$ & $p$ \\
\hline & & $\%$ & $\%$ & $\#$ & $\%$ & & \\
\hline $\begin{array}{c}\text { Online music } \\
\text { multimedia }\end{array}$ & New & 95.1 & 4.9 & 247 & - & - & - \\
\hline \multirow{2}{*}{ Digital music files } & Old & 74.4 & 25.6 & 590 & \multirow{2}{*}{15.4} & \multirow{2}{*}{24.65} & \multirow{2}{*}{0.00} \\
\hline & New & 89.8 & 10.2 & 245 & & & \\
\hline \multirow{2}{*}{ Physical recordings } & Old & 88.7 & 11.3 & 591 & \multirow{2}{*}{-10.8} & \multirow{2}{*}{16.24} & \multirow{2}{*}{0.00} \\
\hline & New & 77.9 & 22.1 & 244 & & & \\
\hline \multirow{2}{*}{$\begin{array}{c}\text { Music/entertainment } \\
\text { news }\end{array}$} & Old & 66.3 & 33.7 & 590 & \multirow{2}{*}{5.2} & \multirow{2}{*}{2.11} & \multirow{2}{*}{0.15} \\
\hline & New & 71.4 & 28.6 & 245 & & & \\
\hline \multirow{2}{*}{ Music multimedia $^{5}$} & Old & 63.9 & 36.1 & 590 & \multirow{2}{*}{-9.0} & \multirow{2}{*}{5.87} & \multirow{2}{*}{0.02} \\
\hline & New & 54.9 & 45.1 & 244 & & & \\
\hline \multirow{2}{*}{$\begin{array}{l}\text { Music-related } \\
\text { software }\end{array}$} & Old & 42.2 & 57.8 & 590 & \multirow{2}{*}{1.6} & \multirow{2}{*}{0.19} & \multirow{2}{*}{0.66} \\
\hline & New & 43.9 & 56.1 & 244 & & & \\
\hline \multirow{2}{*}{ Music magazines } & Old & 38.1 & 61.9 & 588 & \multirow{2}{*}{-0.1} & \multirow{2}{*}{0} & \multirow{2}{*}{0.98} \\
\hline & New & 38.0 & 62.0 & 242 & & & \\
\hline \multirow{2}{*}{ Books on music } & Old & 39.0 & 61.0 & 590 & \multirow{2}{*}{-2.5} & \multirow{2}{*}{0.44} & \multirow{2}{*}{0.51} \\
\hline & New & 36.5 & 63.5 & 241 & & & \\
\hline \multirow{2}{*}{ Sheet music/scores } & Old & 33.5 & 66.5 & 588 & \multirow{2}{*}{-12.8} & \multirow{2}{*}{13.30} & \multirow{2}{*}{0.00} \\
\hline & New & 20.7 & 79.3 & 241 & & & \\
\hline \multirow{2}{*}{$\begin{array}{l}\text { Academic music } \\
\text { journal articles }\end{array}$} & Old & 19.2 & 80.8 & 589 & \multirow{2}{*}{-0.5} & 003 & 086 \\
\hline & New & 18.7 & 81.3 & 241 & & 0.03 & 0.86 \\
\hline
\end{tabular}



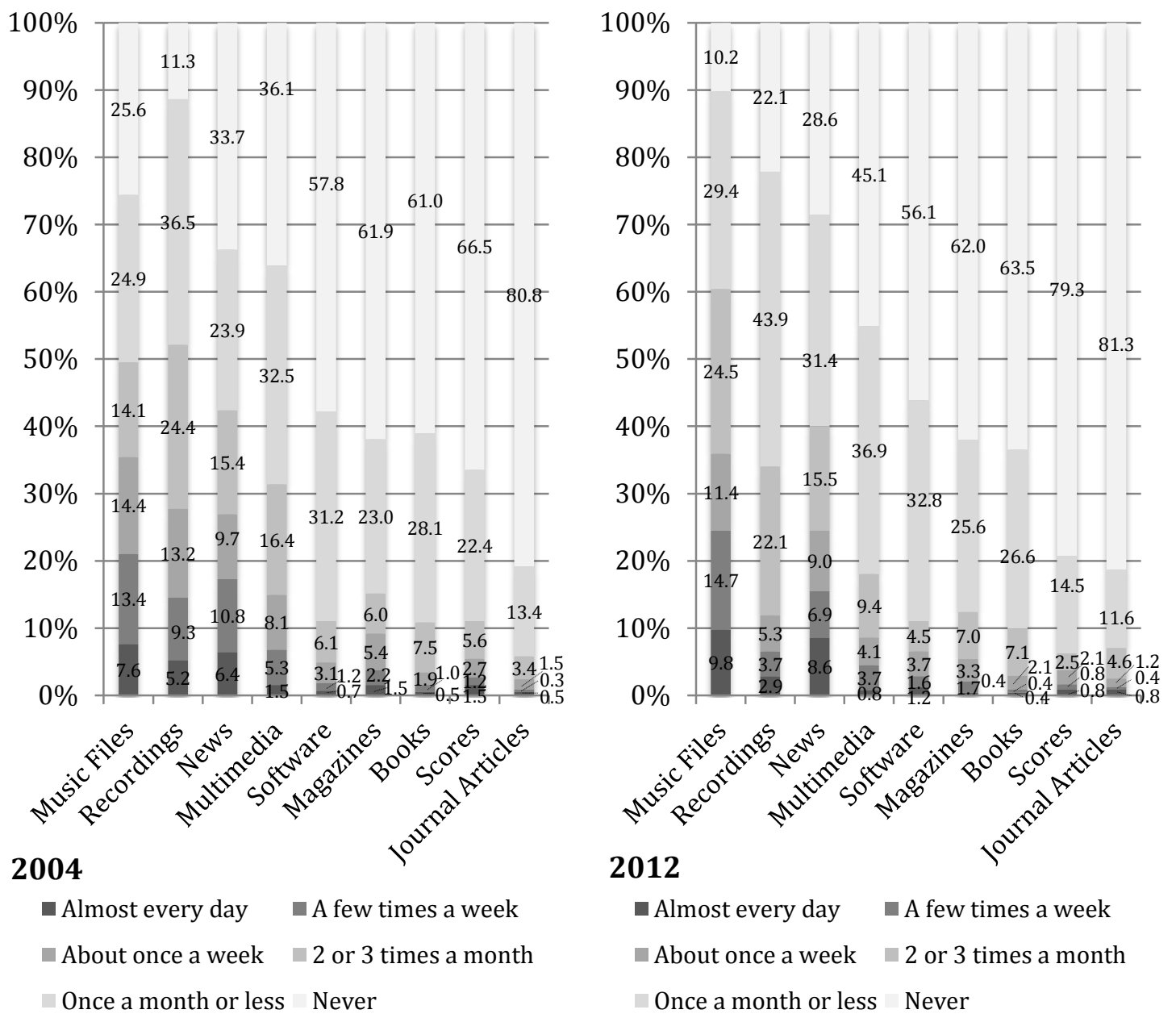

Figure 1. Frequency distribution of music-related information sought

With the emergence of newer music listening devices including smartphones, it is not surprising that digital music files are more frequently sought than physical recordings in the 2012 survey. In addition to the increased proportion of positive responses, the result shows slightly increased frequency of seeking digital music as well: $9.8 \%$ of the respondents from the new survey answered they seek digital music file almost every day and $14.7 \%$ of those answered a few times a week, compared to $7.6 \%$ and $13.4 \%$ respectively in the previous survey. Additionally, examining the frequency of search reveals that the change is quite significant as the respondents in the new survey do seek physical music recordings, but much less frequently than previously. Figure 1 shows that participants who never searched for music recordings increased by $10.8 \%$, and the number of participants who searched music recordings "almost every day," "a few times in a week," "about once a week," and "2 or 3 times in a month," all decreased.

In the new survey, we added one more response option-online music multimedia (e.g., YouTube $^{6}$ videos, music videos on Yahoo! Music ${ }^{7}$ - - to reflect recent trends. Of the 11 different formats of music information, online music-related multimedia was the most frequently sought material in the new survey, even more so than digital music files or physical recordings. Almost all respondents (95.1\%) answered that they have searched for 
"online music multimedia" and $27.5 \%$ in fact do it almost every day. This is strong evidence indicating that the way users experience music on a daily basis has significantly shifted to consuming multimedia incorporating music and not just music itself. In fact, the new survey participants ranked YouTube as the second most preferred music-related service, following Pandora, despite the fact that the website is not designed specifically to provide music content (further discussed in the Favorite Music Websites and Applications section). In addition to online music multimedia, $54.9 \%$ of respondents also answered they sought "music multimedia in other formats (e.g., Blu-ray, DVD, VHS)."

The overall ranking of the preferred types of music information is quite consistent in both surveys, but the frequency of music information search did increase for most items in the new survey. Two notable observations from comparing the results from the two surveys are (a) the reversed ranking between digital music files and music recordings, and (b) the dramatic increase in people's consumption of music multimedia.

\section{Reasons/purposes for seeking music information}

In the previous survey, to listen, identify, acquire, and learn about music were the respondents' top reasons for seeking music information. Based on the proportion of positive responses (Table 3) and the frequency of search (Figure 2), the most common reason in the previous survey was "to listen for entertainment" (94.8\%), which further increased to $98.4 \%$ in the new survey. This growing trend is more clearly observed in the frequency charts (Figure 2). In the previous survey, $27.5 \%$ of the respondents answered that they listen to music for entertainment "almost every day," and 15.5\% answered "a few times a week." In the new survey, however, it increased to $40.4 \%$ responding "almost every day" and 22.8\%, "a few times a week." This was followed by "to build collection" (89.0\%), and "to identify/verify musical work, artist, lyrics, etc." (77.9\%). Known-item searches (i.e., identification/verification) were in fact very common in both surveys. Information seeking to help purchase decisions was also increasingly important for respondents, gaining $11.0 \%$ in the new survey. Obtaining background information on artists and music also became a high priority, with an increase of $9.0 \%$. The proportion of positive responses for seeking information for various uses of music (e.g., for special occasions, electronic gadgets, video clips or slideshows, teaching/instruction) was not as high relative to other reasons, but still not insignificant. 
Table 3. Responses to "How often do you seek music or music information for the following reasons?" (Q8)

\begin{tabular}{|c|c|c|c|c|c|c|c|}
\hline Response & $\begin{array}{l}\text { Survey } \\
\text { version }\end{array}$ & Positive & Negative & Valid N & $\begin{array}{c}\text { Gap } \\
\text { (new-old) }\end{array}$ & $X^{2}$ & $p$ \\
\hline Reason & & $\%$ & $\%$ & \# & $\%$ & & \\
\hline \multirow{2}{*}{$\begin{array}{c}\text { To listen for } \\
\text { entertainment }\end{array}$} & Old & 94.8 & 5.2 & 592 & \multirow{2}{*}{3.6} & \multirow{2}{*}{5.83} & \multirow{2}{*}{0.02} \\
\hline & New & 98.4 & 1.6 & 250 & & & \\
\hline \multirow{2}{*}{$\begin{array}{c}\text { To identify/verify } \\
\text { work, artist, lyrics ,etc. }\end{array}$} & Old & 77.9 & 22.1 & 589 & \multirow{2}{*}{11.7} & \multirow{2}{*}{15.80} & \multirow{2}{*}{0.00} \\
\hline & New & 89.6 & 10.4 & 250 & & & \\
\hline \multirow{2}{*}{ To build collection } & Old & 89.0 & 11.0 & 591 & \multirow{2}{*}{-3.6} & \multirow{2}{*}{2.10} & \multirow{2}{*}{0.15} \\
\hline & New & 85.4 & 14.6 & 247 & & & \\
\hline \multirow{2}{*}{$\begin{array}{c}\text { To learn more about } \\
\text { artist }\end{array}$} & Old & 74.1 & 25.9 & 588 & \multirow{2}{*}{9.0} & \multirow{2}{*}{7.93} & \multirow{2}{*}{0.00} \\
\hline & New & 83.1 & 16.9 & 249 & & & \\
\hline \multirow{2}{*}{$\begin{array}{l}\text { To learn about item } \\
\text { before purchase }\end{array}$} & Old & 70.8 & 29.2 & 586 & \multirow{2}{*}{11.0} & \multirow{2}{*}{11.06} & \multirow{2}{*}{0.00} \\
\hline & New & 81.9 & 18.1 & 248 & & & \\
\hline \multirow{2}{*}{$\begin{array}{c}\text { To learn more about } \\
\text { music }\end{array}$} & Old & 59.7 & 40.3 & 590 & \multirow{2}{*}{12.5} & \multirow{2}{*}{11.78} & \multirow{2}{*}{0.00} \\
\hline & New & 72.2 & 27.8 & 248 & & & \\
\hline \multirow{2}{*}{$\begin{array}{c}\text { To use for special } \\
\text { occasions }\end{array}$} & Old & 38.3 & 61.7 & 590 & \multirow{2}{*}{10.9} & \multirow{2}{*}{8.47} & \multirow{2}{*}{0.00} \\
\hline & New & 49.2 & 50.8 & 246 & & & \\
\hline \multirow{2}{*}{$\begin{array}{l}\text { To learn more about } \\
\text { instrument }\end{array}$} & Old & 41.3 & 58.7 & 588 & \multirow{2}{*}{6.0} & 259 & 011 \\
\hline & New & 47.4 & 52.6 & 247 & & 2.59 & 0.11 \\
\hline Touce for gadoetc & Old & 26.7 & 73.3 & 592 & 183 & 2665 & 000 \\
\hline 10 use ior gangets & New & 44.9 & 55.1 & 247 & 10.3 & 20.05 & 0.00 \\
\hline $\begin{array}{c}\text { To use in video clips or } \\
\text { slideshows }\end{array}$ & New & 43.5 & 56.5 & 246 & - & - & - \\
\hline To listen for & Old & 54.6 & 45.4 & 590 & -101 & 705 & 001 \\
\hline work/study purposes & New & 44.5 & 55.5 & 245 & -10.1 & 1.05 & 0.01 \\
\hline To play at certain & Old & 26.1 & 73.9 & 590 & & 0.14 & 071 \\
\hline places & New & 27.3 & 72.7 & 245 & 1.2 & 0.14 & 0.71 \\
\hline To sing or play a & Old & 27.3 & 72.7 & 593 & 06 & 867 & 000 \\
\hline musical instrument ${ }^{8}$ & New & 17.7 & 82.3 & 248 & -9.6 & 8.67 & 0.00 \\
\hline For use in & Old & 14.0 & 86.0 & 592 & 35 & 163 & 020 \\
\hline teaching/instruction & New & 17.5 & 82.5 & 246 & & & \\
\hline For academic research & Old & 13.0 & 87.0 & 591 & $-32+2+3>0$ & 170 & 019 \\
\hline For academic research & New & 9.8 & 90.2 & 245 & -3.2 & 1.10 & 0.19 \\
\hline
\end{tabular}




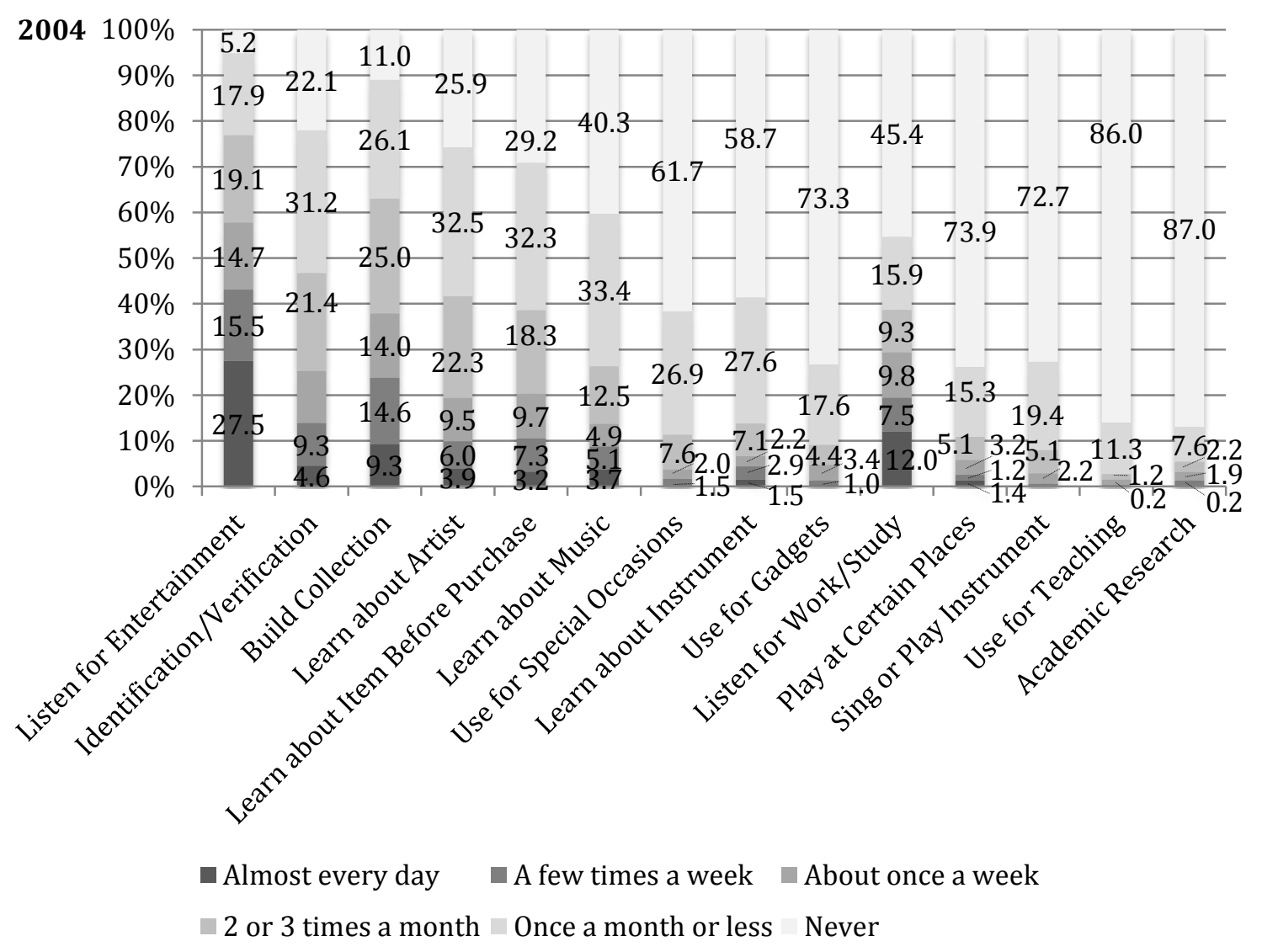




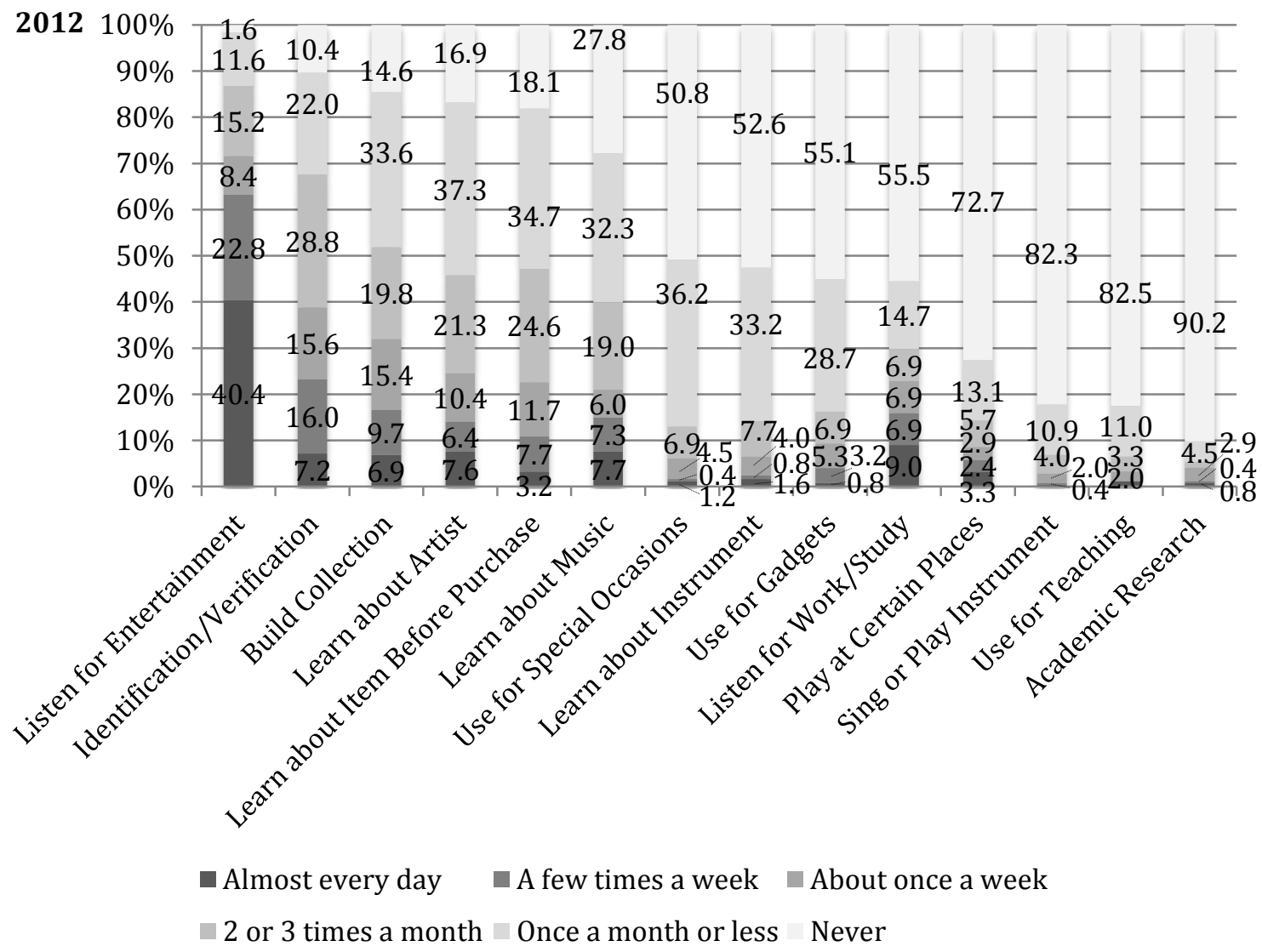

Figure 2. Frequency distribution of responses on reasons for seeking music information

Overall, listening to the music itself and obtaining particular music metadata were more important to respondents than using music for other tasks and events. The ranking for top choices has remained fairly constant across the two surveys, although identification is now ranked higher than collection building. In the case of collection building, we observed a slight decrease in the proportion of positive answers $(-3.6 \%)$ in the new survey and the respondents who engage in this activity also do so less frequently (Figure 2). The proportion of respondents who answered a few times a week or more (aggregation of "almost every day" and "a few times a week") has dropped from $23.9 \%$ to $16.6 \%$. The most significant change in terms of the ranking between the two surveys occurred in "use for gadgets" (26.7\% to $44.9 \%)$, most likely due to the ubiquity of various smart devices.

Ten options showed an increase in the proportion of positive answers (on average, 8.8\%), except for collection building, and the three options that are more closely relevant to people with music-related professions (i.e., listen for work/study purposes, sing or play a musical instrument, and for academic research in a music-related field). This pattern signals the overall increased accessibility to music information online.

\section{The likelihood of seeking particular music information}

We also asked about the respondents' likeliness of seeking 15 different kinds of music information. These include various kinds of descriptive and subject metadata, background and commercial information, as well as opinions from other people. Based on the 
proportion of the positive responses ("very likely" and "somewhat likely"), the top three categories remain unchanged across the two surveys- "Title of works(s)," "Artist information," and "Lyrics," although "Artist information" is now ranked higher than "Lyrics" (Table 4).

Table 4. Responses to "How likely are you to seek the following music information?" (Q16)

\begin{tabular}{|c|c|c|c|c|c|c|c|c|}
\hline $7^{\text {Response }}$ & $\begin{array}{l}\text { Survey } \\
\text { version }\end{array}$ & Positive $^{9}$ & Negative & $\begin{array}{l}\text { Don't } \\
\text { know }\end{array}$ & $\begin{array}{c}\text { Valid } \\
\mathrm{N}\end{array}$ & $\begin{array}{c}\text { Gap } \\
\text { (new-old) }\end{array}$ & $X^{2}$ & $p$ \\
\hline Music info. & & $\%$ & $\%$ & $\%$ & $\#$ & $\%$ & & \\
\hline \multirow{2}{*}{ Title of work(s) } & Old & 91.1 & 7.0 & 1.9 & 573 & \multirow{2}{*}{1.0} & \multirow{2}{*}{1.26} & \multirow{2}{*}{0.53} \\
\hline & New & 92.1 & 7.1 & 0.8 & 239 & & & \\
\hline \multirow{2}{*}{ Artist information } & Old & 76.8 & 21.9 & 1.4 & 585 & \multirow{2}{*}{6.0} & \multirow{2}{*}{4.33} & \multirow{2}{*}{0.11} \\
\hline & New & 82.7 & 16.9 & 0.4 & 243 & & & \\
\hline \multirow{2}{*}{ Lyrics } & Old & 79.2 & 17.7 & 3.1 & 586 & \multirow{2}{*}{-1.1} & \multirow{2}{*}{6.57} & \multirow{2}{*}{0.04} \\
\hline & New & 78.1 & 21.5 & 0.4 & 242 & & & \\
\hline \multirow{2}{*}{$\begin{array}{l}\text { Sample tracks for } \\
\text { listening }\end{array}$} & Old & 68.4 & 27.4 & 4.1 & 580 & \multirow{2}{*}{7.0} & \multirow{2}{*}{6.55} & \multirow{2}{*}{0.04} \\
\hline & New & 75.4 & 23.3 & 1.3 & 240 & & & \\
\hline \multirow{2}{*}{$\begin{array}{c}\text { Information on genre/ } \\
\text { style }\end{array}$} & Old & 52.1 & 43.6 & 4.3 & 583 & \multirow{2}{*}{6.4} & \multirow{2}{*}{6.37} & \multirow{2}{*}{0.04} \\
\hline & New & 58.5 & 40.2 & 1.2 & 241 & & & \\
\hline \multirow{2}{*}{ Track listing } & Old & 61.3 & 34.1 & 4.6 & 586 & \multirow{2}{*}{-2.9} & \multirow{2}{*}{2.45} & \multirow{2}{*}{0.29} \\
\hline & New & 58.3 & 38.8 & 2.9 & 240 & & & \\
\hline \multirow{2}{*}{ Review/rating } & Old & 48.4 & 47.3 & 4.3 & 583 & \multirow{2}{*}{5.8} & \multirow{2}{*}{6.03} & \multirow{2}{*}{0.05} \\
\hline & New & 54.2 & 44.6 & 1.3 & 240 & & & \\
\hline \multirow{2}{*}{$\begin{array}{l}\text { Influences to/from } \\
\text { other artist(s) }\end{array}$} & Old & 44.5 & 51.0 & 4.5 & 582 & 84 & 993 & 0.01 \\
\hline & New & 52.9 & 46.3 & 0.8 & 240 & 0.4 & S & 0.01 \\
\hline Price of item & Old & 51.9 & 42.5 & 5.7 & 584 & -08 & 149 & 0.47 \\
\hline Price or item & New & 51.0 & 45.2 & 3.8 & 239 & -0.8 & 1.49 & 0.41 \\
\hline Information on & Old & 38.8 & 55.6 & 5.7 & 583 & 62 & 782 & 002 \\
\hline different version(s) & New & 45.0 & 53.3 & 1.7 & 240 & 0.2 & 1.02 & 0.02 \\
\hline Artwork/album cover & Old & 32.1 & 62.7 & 5.1 & 585 & 125 & 1379 & 000 \\
\hline Artwork/aidum cover & New & 44.6 & 53.3 & 2.1 & 242 & 12.5 & 13.19 & 0.00 \\
\hline Music background & Old & 42.7 & 53.2 & 4.1 & 583 & & & \\
\hline $\begin{array}{l}\text { information (history, } \\
\text { theory, etc.) }\end{array}$ & New & 41.9 & 55.6 & 2.5 & 241 & -0.8 & 1.45 & 0.48 \\
\hline Links to related & Old & 31.2 & 62.6 & 6.2 & 583 & 9.4 & 974 & \\
\hline websites & New & 40.6 & 56.9 & 2.5 & 239 & 9.4 & 9.14 & 0.01 \\
\hline & Old & 24.2 & 70.0 & 5.8 & 583 & 100 & & \\
\hline & New & 34.2 & 63.3 & 2.5 & 240 & 10.0 & 11.24 & 0.00 \\
\hline label & Old & 18.0 & 76.2 & 5.8 & 583 & 2 & 4.42 & 0.11 \\
\hline Necoriu Iaver & New & 20.5 & 77.0 & 2.5 & 239 & $2 . J$ & $4.4 L$ & 0.11 \\
\hline
\end{tabular}

The option that showed the most drastic increase is "artwork, album cover $(32.1 \%$ to $44.6 \%$ )." This may be due the fact that many online music providers (e.g. Spotify, Pandora) display music album images as visual cues to facilitate search/browse within the site/app.

"Track listing" showed the most decrease from $61.3 \%$ to $58.3 \%$, even though the difference is not statistically significant. This pattern seems reasonable as purchasing individual tracks rather than the whole album is now much more common in the digital music market. However, further exploration of a more qualitative nature will be necessary to verify if this is in fact the cause of this pattern. 
Figure 3 shows the distribution of responses on the likelihood for each category. Overall, the distributions across the two surveys do not appear significant, although we observed a large decrease in the proportion of "very likely" for track listing (-6.8\%), again most likely due to the change in the unit of music purchase in physical and digital formats.

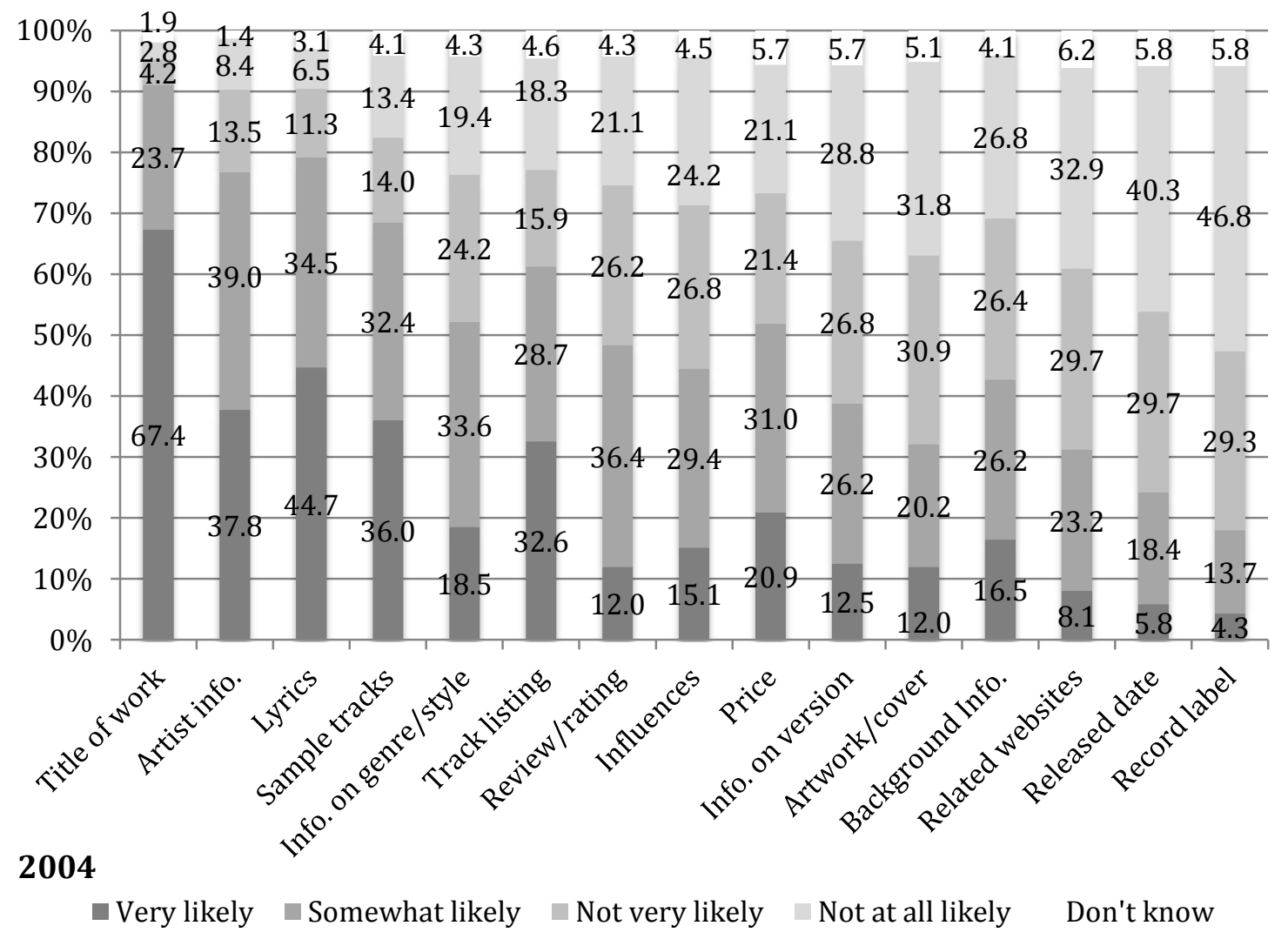




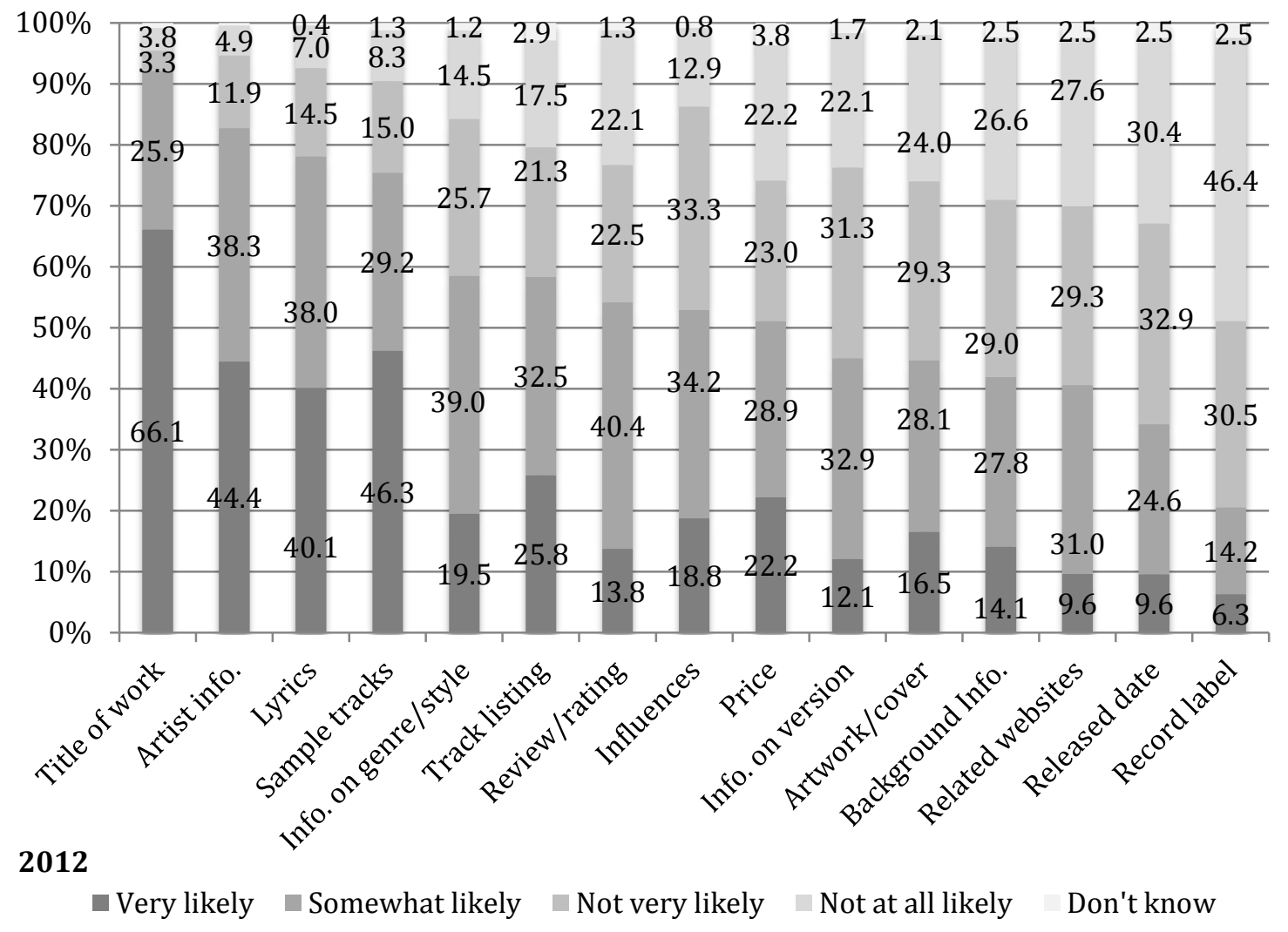

Figure 3. Distribution of the responses on the likelihood of seeking particular music information

\section{Music Information-Seeking Behaviors}

\section{Online music-related activities}

In response to the question asking about the respondents' engagement in particular musicrelated online activities, $96.6 \%$ of the new survey's participants answered that they "listen to streaming music or online radio." This was followed by "read any kind of music information" (90.0\%), "purchase and download music files" (83.1\%), and "visit online music stores" (82.8\%). Compared to the previous survey result, the most notable increase is observed for "purchase and download music files $(+45.4 \%)$." We also observed that the proportion of respondents who said they never purchase digital music files has significantly decreased from $62.3 \%$ to $16.9 \%$ (Figure 4). This signals that more users have embraced the idea of legally purchasing digital music content. This is likely because there are more apps and services for streaming and conveniently purchasing music, and $57.3 \%$ of users in the new survey did answer that they use music-related apps on their mobile phones. On the other hand, the proportion of users purchasing physical music recordings decreased by $10.0 \%$. The proportions for visiting an online music store $(+8.9 \%)$ and downloading free music files (+9.2\%) also increased, indicating the increase in seeking and consuming of digital music overall. It is also noteworthy that listening to music streaming services showed the second-largest increase of $19.0 \%$ in the new survey. This indicates a trend toward greater direct music consumption from streaming services in addition to building and listening to personal music collections (Table 5). 
Table 5. Responses to "How often do you do the following activities online?" (Q2.1)

\begin{tabular}{|c|c|c|c|c|c|c|c|}
\hline Response & $\begin{array}{l}\text { Survey } \\
\text { version }\end{array}$ & Positive & Negative & Valid N & $\begin{array}{c}\text { Gap } \\
\text { (new-old) }\end{array}$ & $X^{2}$ & $p$ \\
\hline Activity & & $\%$ & $\%$ & \# & $\%$ & & \\
\hline \multirow{2}{*}{$\begin{array}{c}\text { Listen to music } \\
\text { streaming/online } \\
\text { radio }\end{array}$} & Old & 77.6 & 22.4 & 557 & \multirow{2}{*}{19.0} & \multirow{2}{*}{42.16} & \multirow[b]{2}{*}{0.00} \\
\hline & New & 96.6 & 3.4 & 232 & & & \\
\hline \multirow{2}{*}{$\begin{array}{l}\text { Read any kind of music } \\
\text { information }\end{array}$} & Old & 86.3 & 13.8 & 560 & \multirow{2}{*}{3.8} & \multirow{2}{*}{2.13} & \multirow{2}{*}{0.14} \\
\hline & New & 90.0 & 10.0 & 231 & & & \\
\hline \multirow{2}{*}{$\begin{array}{c}\text { Purchase and } \\
\text { download music files }\end{array}$} & Old & 37.7 & 62.3 & 559 & \multirow{2}{*}{45.4} & \multirow{2}{*}{134.65} & \multirow{2}{*}{0.00} \\
\hline & New & 83.1 & 16.9 & 231 & & & \\
\hline \multirow{2}{*}{$\begin{array}{l}\text { Visit online music } \\
\text { stores }\end{array}$} & Old & 73.9 & 26.1 & 559 & \multirow{2}{*}{8.9} & \multirow{2}{*}{7.18} & \multirow{2}{*}{0.01} \\
\hline & New & 82.8 & 17.2 & 232 & & & \\
\hline \multirow{2}{*}{$\begin{array}{l}\text { Download free music } \\
\text { files }\end{array}$} & Old & 72.7 & 27.3 & 557 & \multirow{2}{*}{9.2} & \multirow{2}{*}{7.40} & \multirow{2}{*}{0.01} \\
\hline & New & 81.9 & 18.1 & 227 & & & \\
\hline \multirow{2}{*}{$\begin{array}{l}\text { Purchase physical } \\
\text { music recordings }\end{array}$} & Old & 81.2 & 18.8 & 559 & \multirow{2}{*}{-10.0} & \multirow{2}{*}{9.62} & \multirow{2}{*}{0.00} \\
\hline & New & 71.2 & 28.8 & 233 & & & \\
\hline Use mobile music apps & New & 57.3 & 42.7 & 227 & - & - & - \\
\hline $\begin{array}{c}\text { Use cloud music } \\
\text { services }\end{array}$ & New & 49.8 & 50.2 & 223 & - & - & - \\
\hline \multirow{2}{*}{$\begin{array}{l}\text { Visit online music- } \\
\text { related community }\end{array}$} & Old & 38.4 & 61.6 & 562 & \multirow{2}{*}{5.0} & \multirow{2}{*}{1.73} & \multirow{2}{*}{0.19} \\
\hline & New & 43.5 & 56.5 & 230 & & & \\
\hline $\begin{array}{l}\text { Play music-related } \\
\text { video games }\end{array}$ & New & 38.3 & 61.7 & 227 & - & - & - \\
\hline \multirow{2}{*}{$\begin{array}{l}\text { Read/subscribe to } \\
\text { music-related } \\
\text { listservs/mailing list }\end{array}$} & Old & 22.7 & 77.3 & 559 & \multirow{2}{*}{5.8} & \multirow{2}{*}{2.94} & \multirow{2}{*}{0.09} \\
\hline & New & 28.5 & 71.5 & 228 & & & \\
\hline \multirow{2}{*}{$\begin{array}{l}\text { Download sheet } \\
\text { music/scores }\end{array}$} & Old & 30.9 & 69.1 & 553 & \multirow{2}{*}{-10.8} & 022 & 000 \\
\hline & New & 20.1 & 79.9 & 224 & & 9.32 & 0.00 \\
\hline
\end{tabular}

Figure 4 shows the frequency of participants' music-related online activities in more detail. Again, the increased usage of music streaming services is clearly depicted. While $33.2 \%$ of the new survey participants answered that they listen to music streaming or online radio almost every day, only $10.8 \%$ of the previous survey participants did so. Collection building is still an important need as evidenced by the high proportions of respondents obtaining music files and recordings. However, Figure 4 reveals that this happens less frequently, noted by the large proportions of "never" and "once a month or less" for purchasing music files or recordings. 


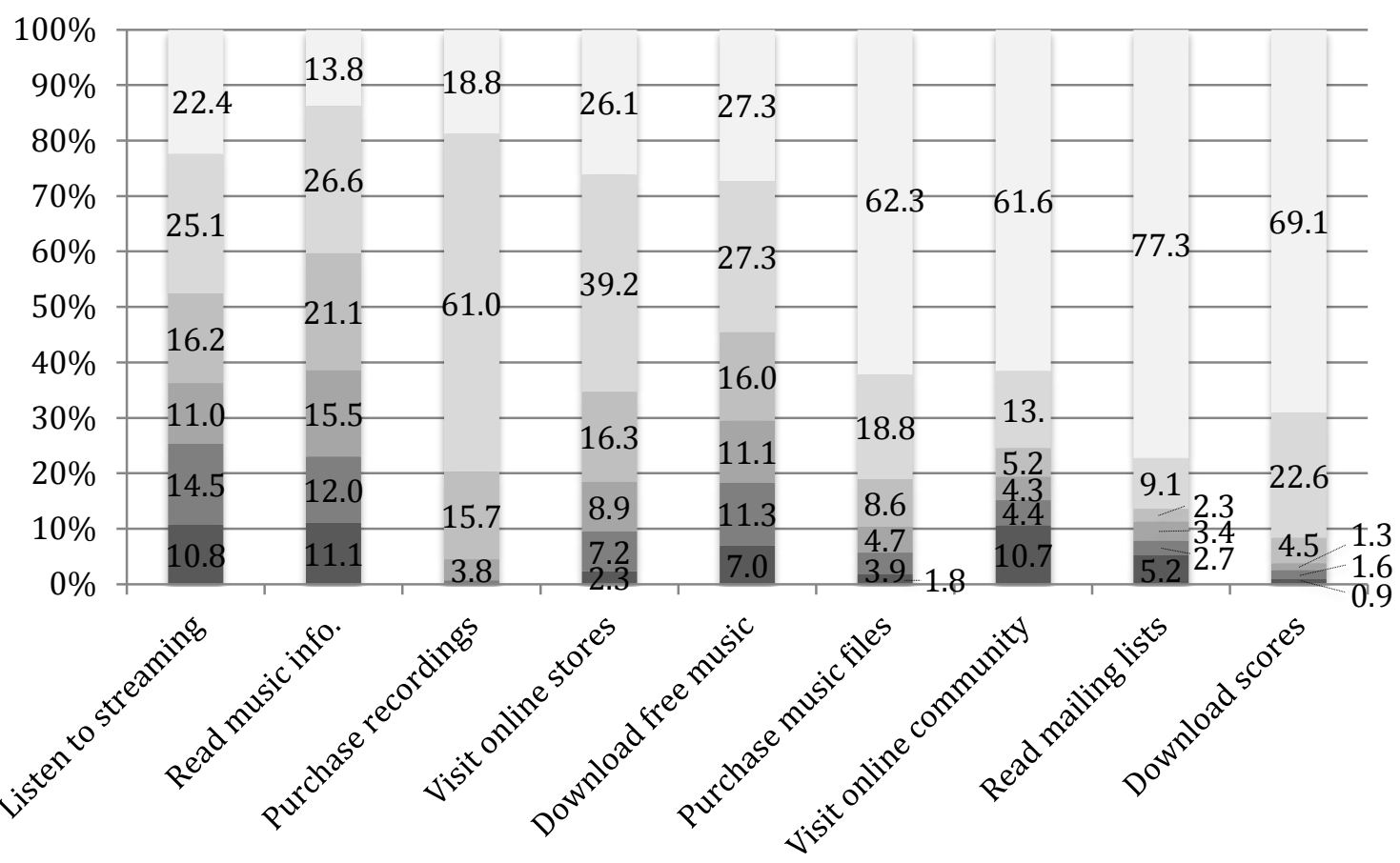

$2004 \square$ Almost every day $\square$ A few times a week $\square$ About once a week

$\square 2$ or 3 times a month $\square$ Once a month or less Never

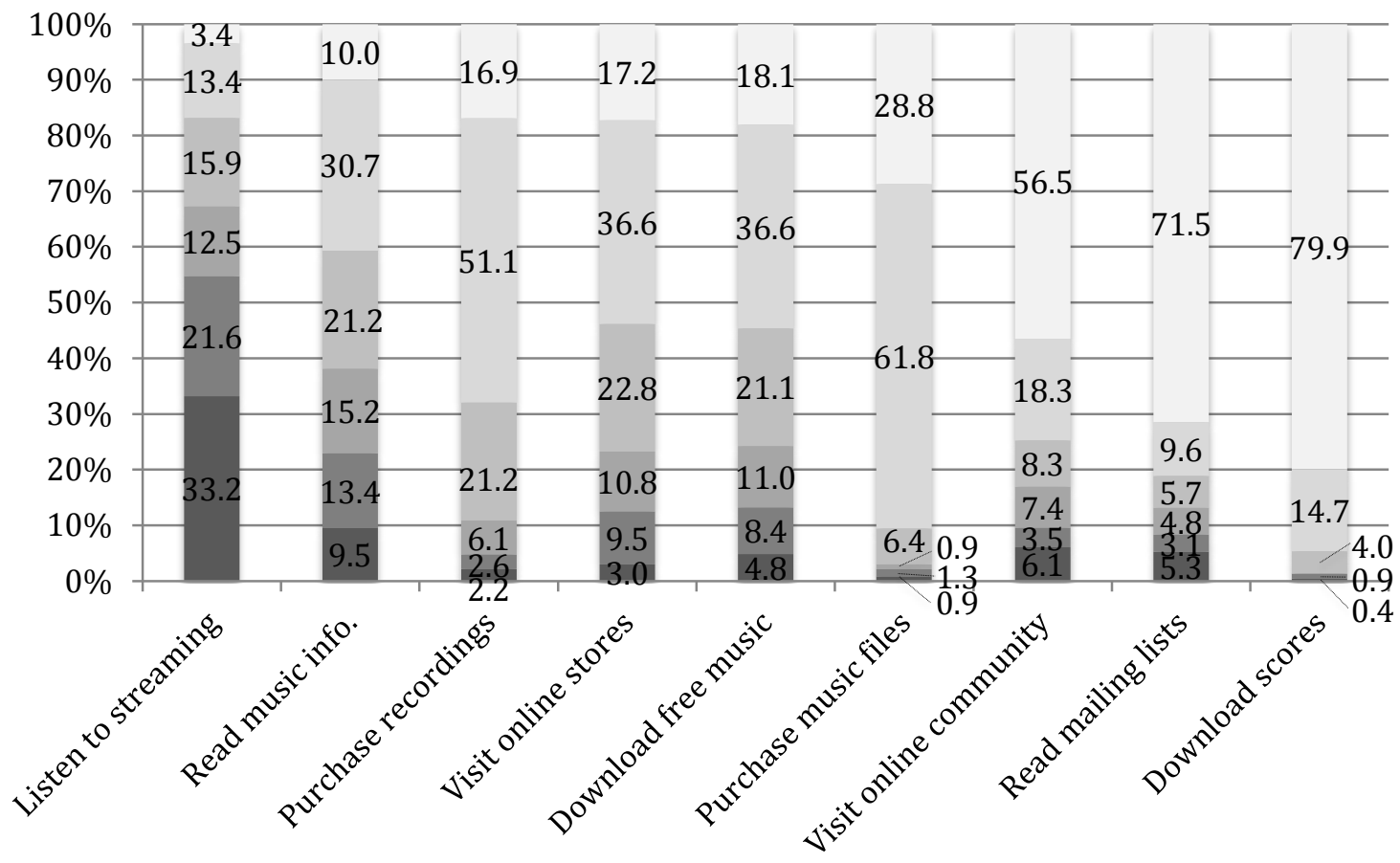

$$
\begin{aligned}
& 2012 \square \text { Almost every day } \square \text { A few times a week } \square \text { About once a week } \\
& \square \text { or } 3 \text { times a month } \square \text { Once a month or less } \quad \text { Never }
\end{aligned}
$$

Figure 4. Frequency distribution of responses on music-related online activities 


\section{Favorite music websites and applications}

An in-depth analysis of responses to the open-ended question asking about respondents' favorite music websites or applications (Q3) and the reasons they like them is presented in Lee and Waterman (2012). A list of qualities particularly valued by respondents in the previous and new surveys is compared in Table 6.

Table 6. The list of qualities of music services valued by users (Table 5 in Lee \& Waterman, 2012, p. 256)

\begin{tabular}{l|c|c|c|c}
\hline \multirow{2}{*}{\begin{tabular}{l|c|c|c} 
Response \\
Quality
\end{tabular}} & \multicolumn{2}{|c|}{$\begin{array}{c}2004 \text { Survey } \\
(\mathrm{N}=646)^{10}\end{array}$} & \multicolumn{2}{c}{$\begin{array}{c}2012 \text { Survey } \\
(\mathrm{N}=644)\end{array}$} \\
\cline { 2 - 5 } & $\#$ & $\%$ & $\#$ & $\%$ \\
\hline Exposure to new things/Serendipity & 18 & 2.8 & 80 & 12.4 \\
\hline Free/Inexpensive & 50 & 7.7 & 68 & 10.6 \\
\hline Ease of access/Convenience & 9 & 1.4 & 52 & 8.1 \\
\hline Customizability/Personalization & 8 & 1.2 & 49 & 7.6 \\
\hline User-friendly/Ease of use & 28 & 4.3 & 46 & 7.1 \\
\hline Comprehensive/Exhaustive coverage & 64 & 9.9 & 37 & 5.7 \\
\hline Variety/Wide selection & 51 & 7.9 & 36 & 5.6 \\
\hline Access to particular style of music & 69 & 10.7 & 28 & 4.3 \\
\hline Compatibility/Use with other devices & 1 & 0.2 & 25 & 3.9 \\
\hline Access to music samples & 18 & 2.8 & 23 & 3.6 \\
\hline Good search/browse functions & 8 & 1.2 & 23 & 3.6 \\
\hline Social/Ability to interact with others & 52 & 8.0 & 22 & 3.4 \\
\hline Matches user's interest/taste & 67 & 10.4 & 21 & 3.3 \\
\hline Good music/content & 61 & 9.4 & 16 & 2.5 \\
\hline Quick/Instant service & 7 & 1.1 & 16 & 2.5 \\
\hline Comparative data/Similar music & 8 & 1.2 & 14 & 2.2 \\
\hline No rights management/restrictions & 0 & 0.0 & 10 & 1.6 \\
\hline Fun/High entertainment value & 2 & 0.3 & 9 & 1.4 \\
\hline Authority/Credibility of information & 7 & 1.1 & 8 & 1.2 \\
\hline Does not require much user input & 1 & 0.2 & 8 & 1.2 \\
\hline Rare/Obscure recordings/information & 17 & 2.6 & 7 & 1.1 \\
\hline Familiarity/Set as default & 8 & 1.2 & 6 & 0.9 \\
\hline Ability to store/archive recordings & 0 & 0.0 & 6 & 0.9 \\
\hline New content/Updated frequently & 48 & 7.4 & 5 & 0.8 \\
\hline Accuracy/Reliability of information & 5 & 0.8 & 5 & 0.8 \\
\hline Access to local information & 5 & 0.8 & 4 & 0.6 \\
\hline Good organization/design & 11 & 1.7 & 3 & 0.5 \\
\hline No or fewer ads & 6 & 0.9 & 3 & 0.5 \\
\hline Other & 12 & 1.9 & 31 & 4.8 \\
\hline
\end{tabular}

The most important quality mentioned in the new survey was the exposure to new music and artists; in other words, serendipitous discovery. This is undoubtedly related to the popularity of systems such as Pandora, Spotify, or Last.FM. Many of the respondents' comments about Pandora suggest that this kind of recommender works well, particularly when the user is interested in specific genres, and wants to play a station as background music. 
"IIt] let's me listen by (specific and often arcane) styles of music that I like and helps me discover new artists (have learned of many many this way)."

"I like Pandora because it exposes me to new music which are similar to the genres I enjoy..."

"Pandora - good white noise (classical, ambient)"

"Pandora - very good for streaming background music at a gathering"

"Pandora - can just leave it on in the background while working. The algorithm does OK based on thumbs up/thumbs down."

"Pandora, ease of use. I work in a bar where I play a large amount of music, it offers me flexibility and ease."

Because many users were exposed and became accustomed to these kinds of services, their expectations seem to also have changed, as serendipitous discovery was not mentioned as often in the 2004 survey. Rather, access to particular styles of music or music that match users' interests or tastes was deemed most important, perhaps reflecting the lack of variety of music that was available online at that time. This also seems related to the sharp decrease in the number of comments expressing value in the comprehensiveness of coverage and good music content, as many of today's music services tend to provide access to a virtually limitless amounts of music content. Some users did make comments related to the comprehensive coverage of music in the 2012 survey, especially when they talked about YouTube (e.g., "youtube has everything," "every song under the sun (is) available," "YouTube has almost anything you can ever think of. Even obscure Japanses (sic) pop songs from the $80^{\prime} s^{\prime}$ " "...I practically never searched for a song I didn't find on their servers.") and Spotify (e.g., "I also like Spotify because it's like having all the music I want without having to buy it," "I also enjoy Spotify's extensive catalogue," "Spotify: I like listening to whatever I want, whenever I want," "Spotify - you can listen to almost any music."). Because of the increased availability of music online, the overall appreciation of the comprehensiveness of music accessible in particular music services seemed to have decreased.

Personalization/customizability was also much more important to current music users than in 2004. Avoiding rights management/restrictions and ability to store or archive recordings were the two new qualities that were reported in 2012. With the increasing number of subscription-based and cloud-based music services, we believe that these are going to continue to be important features for music users (e.g., "Using the Pandora app means that I don't have to download music onto my phone which I think is a hassle sometimes."). The design aspects of the music services such as ease of access or user-friendly features are also mentioned as important qualities to users. This suggests the need for conducting user studies not only focusing on the quality of the search results or recommendations provided by these systems/services, but also a more holistic study evaluating the users' interaction with the systems as a whole. There already exist a number of studies evaluating different MIR systems/services, in particular music playlists or playlist generators (Pauws \& Eggen, 2002; Lee, 2011) or music recommender systems (Barrington et al., 2009). However, studying these systems with a focus on the user-= experience and interactions will provide additional insights for creating successful MIR systems. Compatibility, which was rarely mentioned in the previous survey, is also increasingly becoming an important issue as apps 
are being developed for certain brands of mobile devices. Some of the things mentioned under the other category included "innovative, high quality recordings and writing, different purchase options, providing alerts, being able to listen to the whole album, not posting to Facebook, not hogging resources, directly paying artists, fewer bugs, etc." (Lee \& Waterman, 2012, p. 256).

\section{Physical places visited for music information seeking}

In addition to online activities, we asked about physical places users visit to find music information (Table 7). In the new survey, compared to the proportions of positive responses given for online activities, the overall proportions for physical places were significantly lower. Of the four options, record store was the most common $78.8 \%$ in the previous survey, $56.1 \%$ in the new survey), followed by a friend's or acquaintance's place (72.4\% in the previous survey, $53.2 \%$ in the new survey). Although the order of preferences for physical places was the same in both surveys, the use of them showed statistically significant differences. The number of participants who go to record stores to search for music information decreased by $22.8 \%$, and the proportion of participants who find music information at friend's or acquaintance's place was also reduced by $19.2 \%$. Although the new survey's participants visited libraries more frequently $(12.0 \%)$ than old survey's participants, most of the increase was in the frequency category of "once a month or less" (Figure 5). Responses to the question asking about other places they go for music information seeking (Q6.1) include: events and shows, bookstores, music festivals, musicrelated workshops, my own collection at home, etc. Several respondents mentioned how physical places are irrelevant to them: "I honestly don't go to many physical locations to search for music," "The web-no need to go elsewhere except the record store occasionally," "What record store?"

Table 7. Responses to "How often do you go to the following physical places to search for?" (Q6)

\begin{tabular}{|c|c|c|c|c|c|c|c|}
\hline \multirow[t]{2}{*}{ Response } & $\begin{array}{l}\text { Survey } \\
\text { version }\end{array}$ & Positive & Negative & Valid N & $\begin{array}{c}\text { Gap } \\
\text { (new-old) }\end{array}$ & $X^{2}$ & $p$ \\
\hline & & $\%$ & $\%$ & $\#$ & $\%$ & & \\
\hline \multirow{2}{*}{ Record store } & Old & 78.8 & 21.2 & 591 & \multirow{2}{*}{-22.8} & \multirow{2}{*}{44.76} & \multirow{2}{*}{0.00} \\
\hline & New & 56.1 & 43.9 & 246 & & & \\
\hline \multirow{2}{*}{$\begin{array}{c}\text { Friend's/ } \\
\text { acquaintance's place }\end{array}$} & Old & 72.4 & 27.6 & 591 & \multirow{2}{*}{-19.2} & \multirow{2}{*}{29.00} & \multirow{2}{*}{0.00} \\
\hline & New & 53.2 & 46.8 & 248 & & & \\
\hline \multirow{2}{*}{ Library } & Old & 39.4 & 60.6 & 591 & \multirow{2}{*}{12.0} & \multirow{2}{*}{10.22} & \multirow{2}{*}{0.00} \\
\hline & New & 51.4 & 48.6 & 247 & & & \\
\hline \multirow{2}{*}{ Academic institution } & Old & 24.2 & 75.8 & 591 & \multirow{2}{*}{3.9} & \multirow{2}{*}{1.36} & \multirow{2}{*}{0.24} \\
\hline & New & 28.0 & 72.0 & 246 & & & \\
\hline
\end{tabular}



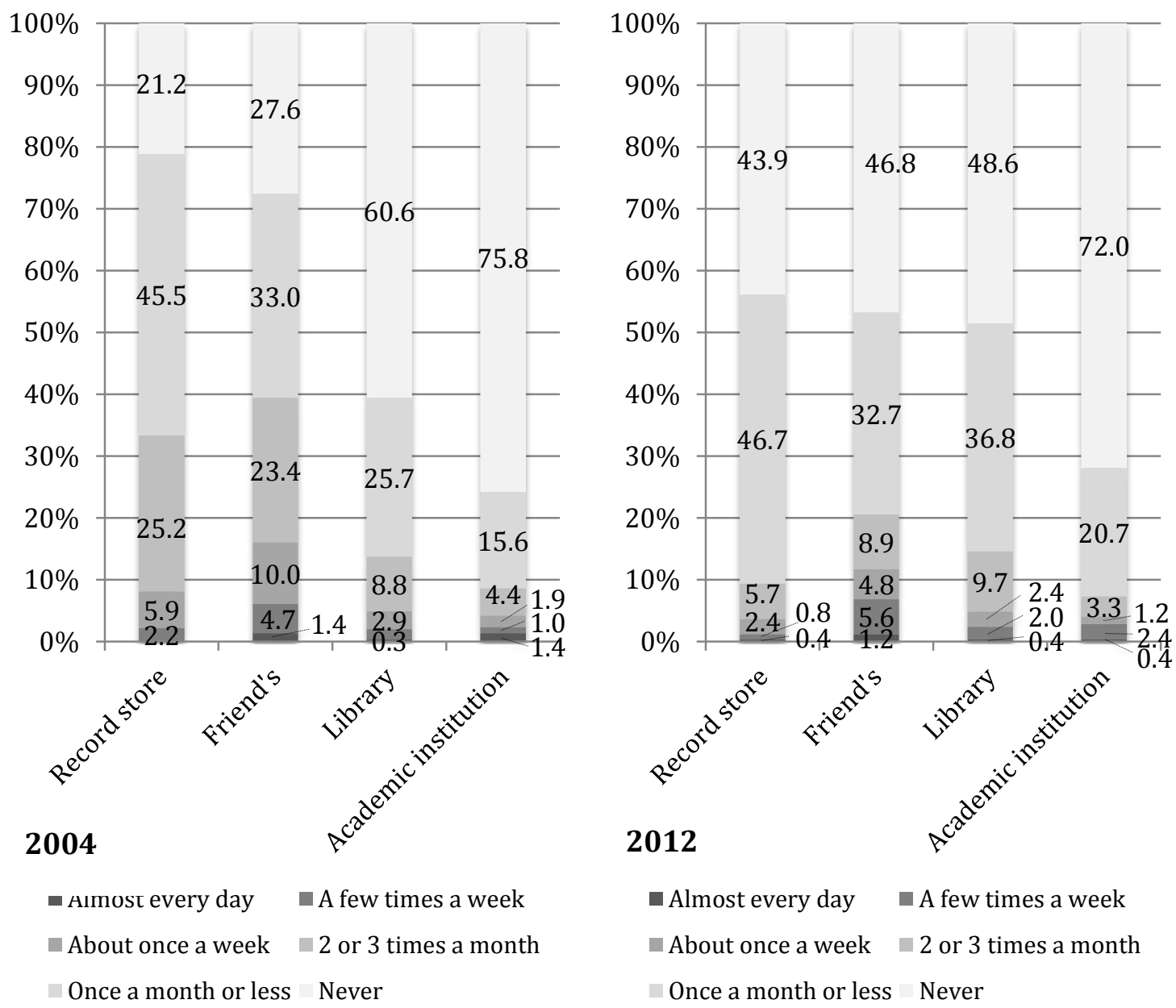

Figure 5. Frequency distribution of responses on physical places visited for music information seeking

\section{People/service consulted for music information seeking}

We asked respondents whom they consult for help when they are seeking music information (Table 8). The availability and approachability of the person seem to be important factors for users to reach out for help. A majority of respondents $(80.9 \%$ in the previous survey and $82.8 \%$ in the new survey) consulted friends or family members when they searched for music information. The most statistically and substantially significant discrepancy we observed between the two surveys is the decrease in the proportion of respondents who seek help from record store staff (44.9\% to $27.8 \%)$. This change can also be verified with the drop in visits to record stores shown in Figure 6 and the observations in Tables 2 and 5, where purchasing physical music recordings was not as important as in the previous study. 
Table 8. Responses to "How often do you ask the following people for help when you search for music or music information?" (Q5)

\begin{tabular}{|c|c|c|c|c|c|c|c|}
\hline \multirow[t]{2}{*}{ Response } & \begin{tabular}{|l|} 
Survey \\
version
\end{tabular} & Positive & Negative & Valid N & $\begin{array}{c}\text { Gap } \\
\text { (new-old) }\end{array}$ & $X^{2}$ & $p$ \\
\hline & & $\%$ & $\%$ & $\#$ & $\%$ & & \\
\hline \multirow{2}{*}{$\begin{array}{l}\text { Friends/family } \\
\text { Members }\end{array}$} & Old & 80.9 & 19.1 & 591 & \multirow{2}{*}{1.9} & \multirow{2}{*}{0.43} & \multirow{2}{*}{0.51} \\
\hline & New & 82.8 & 17.2 & 250 & & & \\
\hline $\begin{array}{c}\text { People on social } \\
\text { network websites }\end{array}$ & New & 60.0 & 40.0 & 250 & - & - & - \\
\hline $\begin{array}{c}\text { Music identification } \\
\text { services }\end{array}$ & New & 42.0 & 58.0 & 250 & - & - & - \\
\hline \multirow{2}{*}{ Musicians } & Old & 32.1 & 67.9 & 592 & \multirow{2}{*}{3.6} & \multirow{2}{*}{1.05} & \multirow{2}{*}{0.30} \\
\hline & New & 35.7 & 64.3 & 249 & & & \\
\hline \multirow{2}{*}{ Record store staff } & Old & 44.9 & 55.1 & 593 & \multirow{2}{*}{-16.1} & \multirow{2}{*}{18.88} & \multirow{2}{*}{0.00} \\
\hline & New & 28.8 & 71.2 & 250 & & & \\
\hline \multirow{2}{*}{$\begin{array}{c}\text { Online music } \\
\text { community members }\end{array}$} & Old & 27.8 & 72.2 & 590 & \multirow{2}{*}{0.7} & \multirow{2}{*}{0.05} & \multirow{2}{*}{0.83} \\
\hline & New & 28.5 & 71.5 & 249 & & & \\
\hline \multirow{2}{*}{ Music librarians } & Old & 11.9 & 88.1 & 590 & \multirow{2}{*}{0.7} & \multirow{2}{*}{0.09} & \multirow{2}{*}{0.77} \\
\hline & New & 12.6 & 87.4 & 246 & & & \\
\hline \multirow{2}{*}{$\begin{array}{l}\text { Teachers/music } \\
\text { instructors }\end{array}$} & Old & 18.1 & 81.9 & 586 & \multirow{2}{*}{-8.3} & \multirow{2}{*}{9.13} & \multirow{2}{*}{0.00} \\
\hline & New & 9.8 & 90.2 & 246 & & & \\
\hline
\end{tabular}



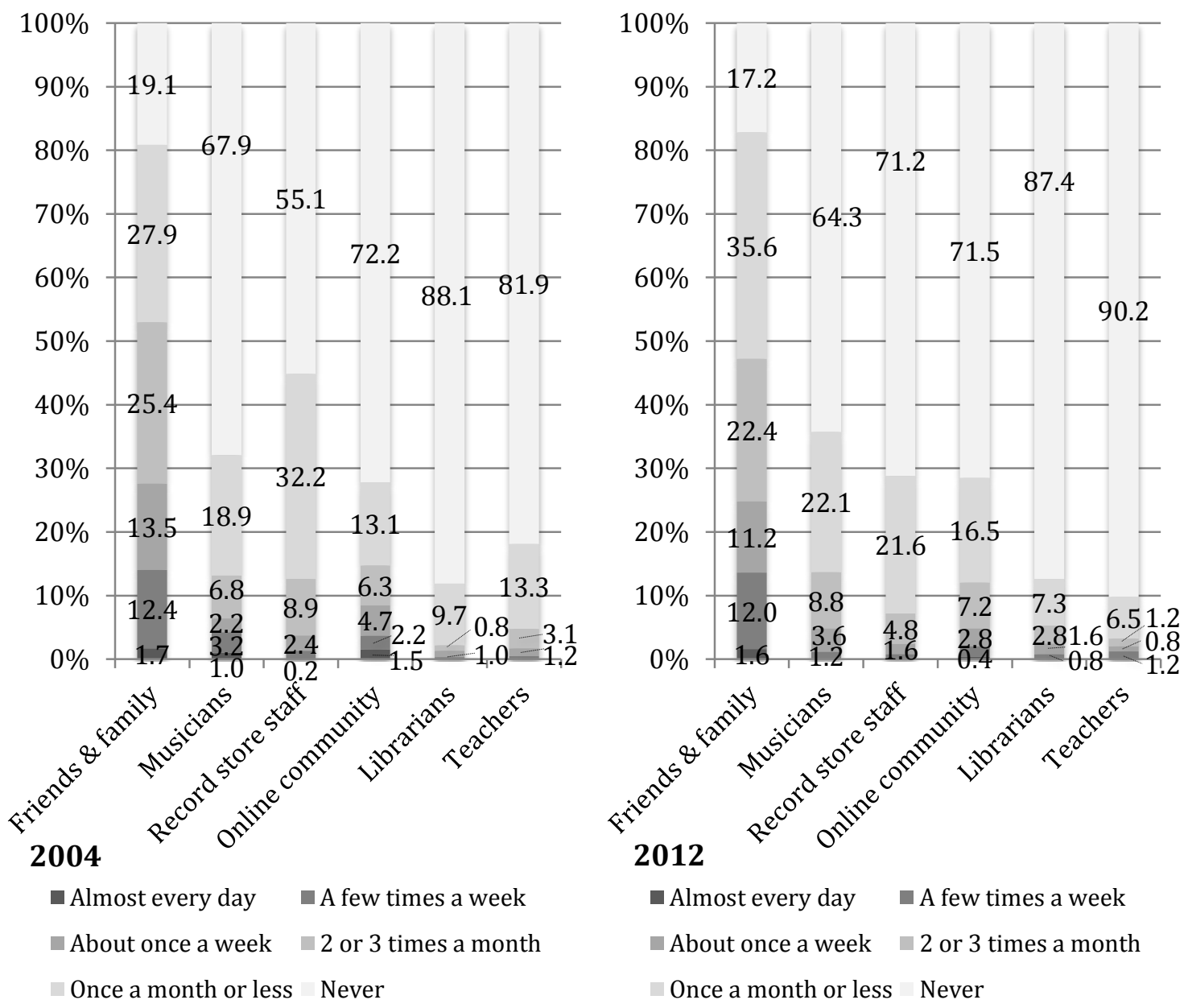

Figure 6. Frequency distribution of responses on people consulted for music information seeking

There were two newly added response options in the new survey-people on social network sites, and music identification services/software. Approximately three out of five $(60.0 \%)$ respondents answered that they have asked people on their social network sites, which may be a mix of friends, family members, co-workers, and acquaintances. Forty-two percent of respondents indicated that they have used music identification services or software. Again, we interpret the prevalence of smartphones as having a considerable influence on people's music information behavior as apps increase the accessibility of these services.

\section{Sources that triggered music information searches}

We were also interested in understanding how often users' serendipitous exposure to music leads them to conducting actual music information searches (Table 9). Radio show (91.3\%) was the most common source for triggering music information searches in the new survey, which was ranked second, following friend's or acquaintance's place (85.6\%), in the 
previous survey. The relevance of radio to users is still strong despite the increasing availability of online music streaming services. In fact, the proportion of positive responses for radio show (91.3\%) was higher than online streaming music service $(82.2 \%)$ in the 2012 survey. Analyzing user data from a follow-up study in which we conducted in-depth interviews of 40 users on their preferred music services and observed their interactions with music services in think-aloud sessions (Lee \& Price, in press) revealed that this may be closely related to people's music listening in cars. Rather than trying to navigate or explore steaming services while they are driving, or figuring out how to play music in the car using their phone, radio often sufficed as a "good enough" source for playing music in the background.

Table 9. Responses to "How often do you search for music you heard from the following sources?" (Q7)

\begin{tabular}{|c|c|c|c|c|c|c|c|}
\hline \multirow[b]{2}{*}{ Place/event } & $\begin{array}{l}\text { Survey } \\
\text { version }\end{array}$ & Positive & Negative & Valid N & $\begin{array}{c}\text { Gap } \\
\text { (new-old) }\end{array}$ & $X^{2}$ & $p$ \\
\hline & & $\%$ & $\%$ & $\#$ & $\%$ & & \\
\hline \multirow{2}{*}{ Radio show } & Old & 81.2 & 18.8 & 589 & \multirow{2}{*}{10.1} & \multirow{2}{*}{12.98} & \multirow{2}{*}{0.00} \\
\hline & New & 91.3 & 8.8 & 240 & & & \\
\hline \multirow{2}{*}{$\begin{array}{c}\text { TV show/ } \\
\text { movie/animation }\end{array}$} & Old & 76.8 & 23.2 & 591 & \multirow{2}{*}{5.9} & \multirow{2}{*}{3.64} & \multirow{2}{*}{0.06} \\
\hline & New & 82.7 & 17.3 & 249 & & & \\
\hline $\begin{array}{l}\text { Online streaming } \\
\text { music service }\end{array}$ & New & 82.2 & 17.8 & 247 & - & - & - \\
\hline Online video clips & New & 81.9 & 18.1 & 248 & - & - & - \\
\hline \multirow{2}{*}{ Public places } & Old & 68.9 & 31.1 & 591 & \multirow{2}{*}{7.4} & \multirow{2}{*}{4.72} & \multirow{2}{*}{0.03} \\
\hline & New & 76.3 & 23.7 & 249 & & & \\
\hline \multirow{2}{*}{$\begin{array}{c}\text { Friend's/ } \\
\text { acquaintance's place }\end{array}$} & Old & 85.6 & 14.4 & 591 & \multirow{2}{*}{-10.2} & \multirow{2}{*}{29.00} & \multirow{2}{*}{0.00} \\
\hline & New & 75.4 & 24.6 & 248 & & & \\
\hline \multirow{2}{*}{ Concert/recital } & Old & 67.6 & 32.4 & 586 & \multirow{2}{*}{-4.0} & \multirow{2}{*}{1.26} & \multirow{2}{*}{0.26} \\
\hline & New & 63.6 & 36.4 & 247 & & & \\
\hline \multirow{2}{*}{$\begin{array}{c}\text { Advertisement/ } \\
\text { commercial }\end{array}$} & Old & 61.6 & 38.4 & 594 & \multirow{2}{*}{1.8} & \multirow{2}{*}{0.24} & \multirow{2}{*}{0.62} \\
\hline & New & 63.4 & 36.6 & 246 & & & \\
\hline \multirow{2}{*}{ Special occasion } & Old & 50.4 & 49.6 & 591 & \multirow{2}{*}{7.9} & \multirow{2}{*}{4.34} & \multirow{2}{*}{0.04} \\
\hline & New & 58.3 & 41.7 & 247 & & & \\
\hline $\begin{array}{l}\text { Music-related video } \\
\text { games }\end{array}$ & New & 27.9 & 72.1 & 247 & - & - & - \\
\hline
\end{tabular}

The option that showed the largest discrepancy between the old survey and the new survey was "friend's/acquaintance's place" (-10.2\%), although the proportion was still high in the new survey (75.4\%). This was the most common source in the previous survey, but is ranked sixth in the new survey. The findings also showed that the new survey participants discover music more often from "radio show" (81.2\% to 91.3\%), "special occasion" (50.4\% to $58.3 \%$ ), and "public places" (68.9\% to $76.3 \%)$. The decrease in friend's/acquaintance's place may be related to the fact that music recommendations are commonly made on social media, and some music services allow people to see what music their friends or acquaintances are currently listening to, increasing virtual exposure. We suspect that the pattern we are observing represents a shift in social engagement away from physical places to online, rather than a decrease of social influences in people's music information seeking. Other sources mentioned by respondents include: podcasts, blog or news articles, postings on social network sites, gym, dance classes, etc. In particular, through the open-ended answer option, several participants mentioned how useful podcasts were in the new survey: 
“...THE most important source for net-based music listening: PODCASTS! I'm subscribed to 20 weekly podcasts."

"One of my most rewarding sources of music is podcasts: I can find shows catering to a wide variety of tastes, as well as narrowing down to specific genres or purposes for music. Some favorites include Sound Opinions, NPR Second Stage, Coverville, and several KEXP podcasts."

Overall, the frequency distribution of responses stayed fairly consistent across the two surveys (Figure 7).
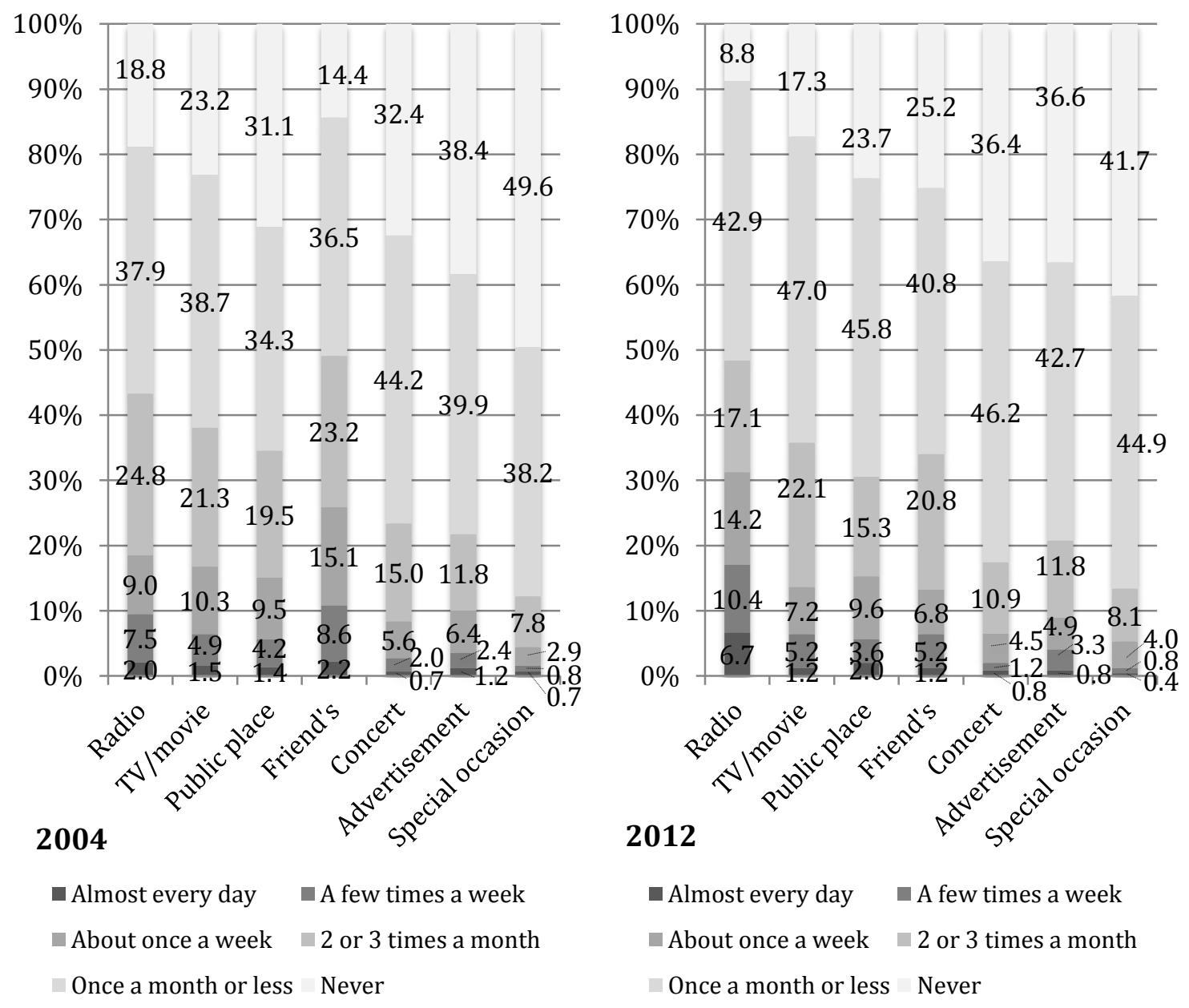

Figure 7. Frequency distribution of responses on sources that triggered music information seeking

\section{Preferred search/browse options}

We also asked respondents how likely it is that they would use 28 different kinds of music browse/search options (Table 10). Based on the proportion of the positive responses, the top two categories remain unchanged across the two surveys-performer and title of works. "Recommendations from others" gained $14.3 \%$ in the new survey and is now the 
third-highest ranked option, indicating the growing importance of social influence in music information seeking. "Recommendations from recommender systems" also received 61.6\% of positive responses, supporting the importance of music recommendations to users in general. The option "purchase patterns" showed the most significant increase in the proportion of positive responses $(+27.0 \%)$, both substantially and statistically. Additionally, we observed a $24.8 \%$ increase in the response "somewhat likely" and $2.1 \%$ in "very likely" in the new survey (Figure 8). This may be due to the fact that more users are accustomed to music services/stores tracking their music consumption behaviors for making recommendations. Artist/music similarity and genre also remain important as they are ranked at the top of the list in both surveys.

Table 10. Responses to "When you search for music or music information, how likely are you to use the following search/browse options if they were available to you?" (Q15)

\begin{tabular}{|c|c|c|c|c|c|c|c|c|}
\hline Response & $\begin{array}{l}\text { Survey } \\
\text { version }\end{array}$ & Positive & $\begin{array}{c}\text { Negativ } \\
\text { e }\end{array}$ & $\begin{array}{l}\text { Don't } \\
\text { know }\end{array}$ & $\begin{array}{c}\text { Valid } \\
\mathrm{N}\end{array}$ & $\begin{array}{c}\text { Gap } \\
\text { (new-old) }\end{array}$ & $X^{2}$ & $p$ \\
\hline Option & & $\%$ & $\%$ & $\%$ & \# & $\%$ & & \\
\hline \multirow{2}{*}{ Performer } & Old & 95.8 & 3.4 & 0.8 & 591 & \multirow{2}{*}{-1.0} & \multirow{2}{*}{1.02} & \multirow{2}{*}{0.60} \\
\hline & New & 94.7 & 3.6 & 1.6 & 247 & & & \\
\hline \multirow{2}{*}{ Title } & Old & 91.9 & 6.6 & 1.5 & 592 & \multirow{2}{*}{-2.4} & \multirow{2}{*}{1.41} & \multirow{2}{*}{0.49} \\
\hline & New & 89.5 & 8.9 & 1.6 & 247 & & & \\
\hline \multirow{2}{*}{$\begin{array}{l}\text { Recommendations } \\
\text { from other people }\end{array}$} & Old & 63.0 & 33.8 & 3.2 & 586 & \multirow{2}{*}{14.3} & \multirow{2}{*}{17.14} & \multirow{2}{*}{0.00} \\
\hline & New & 77.3 & 21.9 & 0.8 & 242 & & & \\
\hline \multirow{2}{*}{ Lyrics } & Old & 71.4 & 25.5 & 3.1 & 581 & \multirow{2}{*}{4.5} & \multirow{2}{*}{2.00} & \multirow{2}{*}{0.37} \\
\hline & New & 75.9 & 22.0 & 2.0 & 245 & & & \\
\hline \multirow{2}{*}{ Similar artist } & Old & 59.8 & 36.8 & 3.4 & 584 & \multirow{2}{*}{9.8} & \multirow{2}{*}{7.03} & \multirow{2}{*}{0.03} \\
\hline & New & 69.5 & 28.0 & 2.5 & 243 & & & \\
\hline \multirow{2}{*}{ Similar music } & Old & 53.6 & 42.1 & 4.3 & 584 & \multirow{2}{*}{12.8} & \multirow{2}{*}{12.00} & \multirow{2}{*}{0.00} \\
\hline & New & 66.4 & 29.5 & 4.1 & 241 & & & \\
\hline \multirow{2}{*}{ Genre/style } & Old & 63.0 & 33.2 & 3.8 & 581 & \multirow{2}{*}{2.0} & \multirow{2}{*}{0.35} & \\
\hline & New & 65.0 & 31.7 & 3.3 & 243 & & & 0.84 \\
\hline $\begin{array}{l}\text { Recommendations } \\
\text { from recommender } \\
\text { systems }\end{array}$ & New & 61.6 & 36.4 & 2.1 & 242 & - & - & - \\
\hline Purchace natternc & Old & 22.2 & 68.0 & 9.8 & 581 & 270 & 6110 & 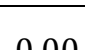 \\
\hline Purchase patterns & New & 49.2 & 47.1 & 3.7 & 242 & 27.0 & 61.19 & 0.00 \\
\hline & Old & 55.6 & 39.6 & 4.8 & 586 & & & \\
\hline Creator & New & 45.1 & 51.2 & 3.7 & 246 & -10.5 & 9.58 & 0.01 \\
\hline & Old & 40.2 & 53.3 & 6.5 & 582 & & & \\
\hline Associated usage & New & 42.3 & 53.1 & 4.6 & 241 & 2.1 & 1.29 & 0.52 \\
\hline & Old & 31.0 & 59.4 & 9.6 & 584 & & & \\
\hline Version & New & 40.0 & 50.0 & 10.0 & 240 & 9.0 & 6.80 & 0.03 \\
\hline & Old & 26.5 & 67.3 & 6.2 & 584 & & & \\
\hline Popularity & New & 39.4 & 58.1 & 2.5 & 241 & 12.9 & 16.10 & 0.00 \\
\hline & Old & 26.4 & 65.7 & 7.9 & 583 & & & \\
\hline Mood & New & 39.2 & 56.7 & 4.2 & 240 & 12.8 & 14.84 & 0.00 \\
\hline & Old & 25.9 & 67.4 & 6.7 & 582 & & & \\
\hline Time period & New & 37.9 & 58.0 & 4.1 & 243 & 11.9 & 12.50 & 0.00 \\
\hline & Old & 23.7 & 71.0 & 5.3 & 582 & & & \\
\hline Country & New & 33.7 & 61.3 & 4.9 & 243 & 10.0 & 8.86 & 0.01 \\
\hline Langurge & Old & 21.6 & 71.1 & 7.4 & 584 & 111 & 1126 & \\
\hline Language & New & 32.6 & 60.7 & 6.6 & 242 & 11.1 & 11.26 & 0.00 \\
\hline
\end{tabular}




\begin{tabular}{|c|c|c|c|c|c|c|c|c|}
\hline \multirow[b]{2}{*}{ Option } & $\begin{array}{l}\text { Survey } \\
\text { version }\end{array}$ & Positive & $\begin{array}{c}\text { Negativ } \\
\mathrm{e}\end{array}$ & $\begin{array}{l}\text { Don't } \\
\text { know }\end{array}$ & $\begin{array}{c}\text { Valid } \\
\mathrm{N}\end{array}$ & $\begin{array}{c}\text { Gap } \\
\text { (new-old) }\end{array}$ & $X^{2}$ & $p$ \\
\hline & & $\%$ & $\%$ & $\%$ & $\#$ & $\%$ & & \\
\hline $\begin{array}{l}\text { Music identification } \\
\text { service }\end{array}$ & New & 30.5 & 60.7 & 8.8 & 239 & - & - & - \\
\hline \multirow{2}{*}{$\begin{array}{l}\text { Place where music } \\
\text { heard }\end{array}$} & Old & 20.2 & 71.5 & 8.2 & 583 & \multirow{2}{*}{9.7} & \multirow{2}{*}{10.58} & \multirow{2}{*}{0.01} \\
\hline & New & 29.9 & 65.2 & 4.9 & 244 & & & \\
\hline \multirow{2}{*}{ Year } & Old & 15.9 & 77.8 & 6.3 & 586 & \multirow{2}{*}{12.9} & \multirow{2}{*}{19.18} & \multirow{2}{*}{0.00} \\
\hline & New & 28.8 & 67.5 & 3.7 & 243 & & & \\
\hline \multirow{2}{*}{$\begin{array}{c}\text { Singing/ } \\
\text { humming a melody }\end{array}$} & Old & 30.5 & 60.8 & 8.7 & 584 & \multirow{2}{*}{-4.5} & \multirow{2}{*}{2.98} & \multirow{2}{*}{0.23} \\
\hline & New & 26.0 & 67.1 & 6.9 & 246 & & & \\
\hline \multirow{2}{*}{ Theme } & Old & 29.9 & 64.1 & 6.0 & 585 & \multirow{2}{*}{-6.6} & \multirow{2}{*}{5.61} & \multirow{2}{*}{0.06} \\
\hline & New & 23.4 & 72.5 & 4.1 & 244 & & & \\
\hline \multirow{2}{*}{ Instrument } & Old & 22.7 & 70.1 & 7.2 & 586 & \multirow{2}{*}{0.5} & \multirow{2}{*}{1.34} & \multirow{2}{*}{0.51} \\
\hline & New & 23.2 & 71.8 & 5.0 & 241 & & & \\
\hline \multirow{2}{*}{ Occasions to use } & Old & 21.6 & 69.6 & 8.7 & 583 & \multirow{2}{*}{-4.1} & \multirow{2}{*}{3.77} & \multirow{2}{*}{0.15} \\
\hline & New & 17.5 & 76.3 & 6.3 & 240 & & & \\
\hline \multirow{2}{*}{ Tempo } & Old & 13.0 & 77.2 & 9.8 & 583 & \multirow{2}{*}{3.1} & \multirow{2}{*}{1.41} & \multirow{2}{*}{0.49} \\
\hline & New & 16.2 & 74.3 & 9.5 & 241 & & & \\
\hline \multirow{2}{*}{ Record label } & Old & 15.0 & 79.7 & 5.3 & 585 & \multirow{2}{*}{0.9} & \multirow{2}{*}{0.61} & \multirow{2}{*}{0.74} \\
\hline & New & 15.9 & 80.0 & 4.1 & 245 & & & \\
\hline Vocal ranoe/aender & Old & 14.7 & 76.7 & 8.6 & 584 & -04 & 267 & 026 \\
\hline vocal range/gender & New & 14.3 & 80.3 & 5.3 & 244 & -0.4 & 2.67 & 0.26 \\
\hline Koubond innut & Old & 11.4 & 75.3 & 13.3 & 578 & 02 & 006 & 007 \\
\hline кеуроara input & New & 11.7 & 74.5 & 13.8 & 239 & 0.3 & 0.06 & 0.97 \\
\hline
\end{tabular}

Overall, using the basic descriptive metadata (except for lyrics, which can arguably count as part of the music itself) was the most preferred method for the respondents. This is consistent with the findings from studies that analyzed online user questions (Bainbridge et al., 2003; Lee, 2010a) with regard to the importance of descriptive metadata. The least used methods (e.g., using keyboard input, vocal range/gender, record label, tempo) also tend to be consistent across both surveys. The fact that record label is one of the least used methods in both surveys reflects the way people commonly identify music; rather than remembering which company published the music, they seem to remember the descriptive data about the music itself such as the work title or artist name. 


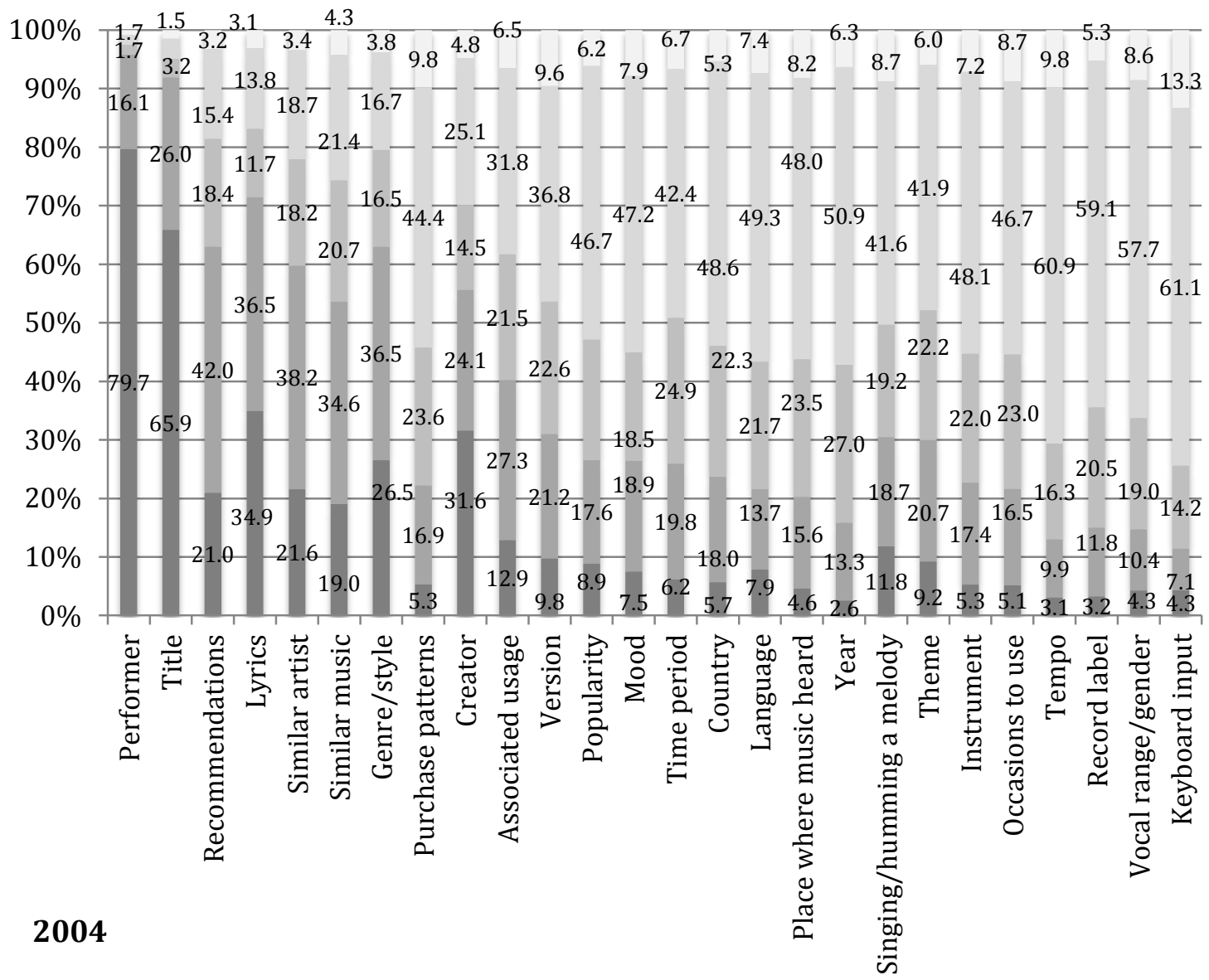

Very likely $\square$ Somewhat likely $\square$ Not very likely $\square$ Not at all likely Don't know 


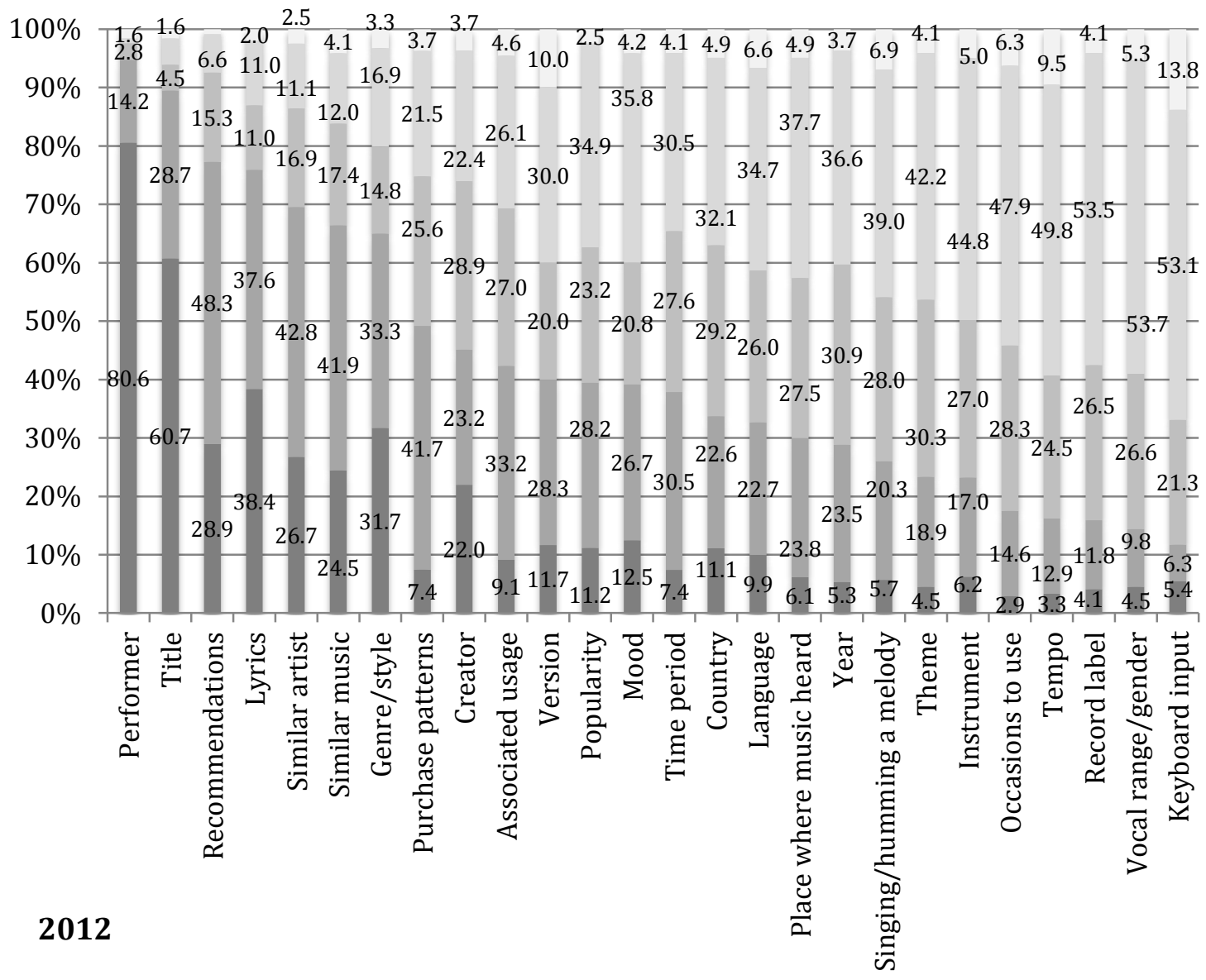

Very likely $\square$ Somewhat likely $\square$ Not very likely $\square$ Not at all likely Don't know

Figure 8. Distribution of the responses on the likelihood of using search/browse options

\section{Music Organization and Collection}

\section{Size of Music Collection (Physical vs. Digital)}

The questions discussed in this section were only asked in the new survey. We asked participants about the size of their music collection, asking them to provide an estimated number of recordings they own for their physical collection, and the number of music files and the amount of disk space they use for their digital collection. Of all participants, $76.3 \%$ said they own a digital music collection and $49.0 \%$ own a physical music collection, again strongly signaling the shift from physical to digital music format. Thirty percent of respondents only had a digital collection versus $3.7 \%$ who only had a physical collection. The proportion of respondents who did not own a music collection was $20.3 \%$, which is not trivial, considering their high interest in music. Regarding the size of the collection, the median value was 200 for physical recordings and 3,000 for digital music files (or $20 \mathrm{~GB}$ ) (Table 11). 
Table 11. Responses to "How big is your physical (Q9.1)/digital music collection (Q10.1)?"

\begin{tabular}{c|c|c|c}
\hline & $\begin{array}{c}\text { Physical collection size } \\
(\#)\end{array}$ & $\begin{array}{c}\text { Digital collection size } \\
(\#)\end{array}$ & $\begin{array}{c}\text { Digital collection size } \\
(\mathrm{Gb})\end{array}$ \\
\hline First quartile & 98 & 1,000 & 8 \\
\hline Median & 200 & 3,000 & 20 \\
\hline Third quartile & 463 & 8,000 & 59 \\
\hline Average & 660 & 10,474 & 1,071 \\
\hline Standard deviation & 1,626 & 40,863 & 12,368 \\
\hline Valid N & 123 & 168 & 150 \\
\hline
\end{tabular}

We also investigated how the average size of physical and digital collections correlates with the respondents' level of interest in music (Q11) (Table 12). Naturally, avid listeners and performers, and people who are musically passionate tended to have a larger music collection in physical or digital format. However, the discrepancies between avid and casual listeners/performers were much more prominent regarding the size of digital collection than physical collection. Participants were able to select multiple response options for Q11, and therefore there could be an issue of multicollinearity. A follow-up survey in which participants are asked to strictly identify themselves as either avid or casual users with respect to music listening, performing, and overall interest would help further verify this pattern.

Table 12. Correlation of collection size and respondents' level of interest in music

\begin{tabular}{c|c|c|c|c|c|c}
\hline & $\begin{array}{c}\text { Avid } \\
\text { listener }\end{array}$ & $\begin{array}{c}\text { Casual } \\
\text { listener }\end{array}$ & $\begin{array}{c}\text { Avid } \\
\text { performer }\end{array}$ & $\begin{array}{c}\text { Casual } \\
\text { performer }\end{array}$ & $\begin{array}{c}\text { Musically } \\
\text { passionate }\end{array}$ & $\begin{array}{c}\text { Musically } \\
\text { curious }\end{array}$ \\
\hline $\begin{array}{c}\text { Avg. size of } \\
\text { physical collection }\end{array}$ & 582 & 517 & 1,000 & 682 & 940 & 750 \\
\hline $\begin{array}{c}\text { Avg. size of digital } \\
\text { collection (\#) }\end{array}$ & 13,177 & 3,691 & 52,917 & 18,940 & 25,468 & 5,458 \\
\hline $\begin{array}{c}\text { Avg. size of digital } \\
\text { collection (Gb) }\end{array}$ & 1,398 & 31 & 305 & 63 & 75 & 37 \\
\hline
\end{tabular}

\section{Organization and Management of Music Collection}

We also asked how respondents primarily organize their physical and digital music collections (Table 13). Forty-nine percent of respondents answered that they own a physical collection and $76 \%$ own a digital collection. A chi-square goodness-of-fit test confirmed that the difference in distributions for overlapping categories for physical versus digital collections is statistically significant $\left(\mathrm{p}<.001, \mathrm{df}=7, \chi^{2}=112.33\right)$. The distribution of organization methods for digital music collection is much more skewed than physical music collection. 
Table 13. Responses to "How is your physical (Q9.2)/digital music collection (Q10.2) organized?"

\begin{tabular}{c||c|c|c}
\hline \multirow{2}{*}{} & $\begin{array}{c}\text { Physical } \\
(\mathrm{N}=120)\end{array}$ & $\begin{array}{c}\text { Digital } \\
(\mathrm{N}=184)\end{array}$ & $\begin{array}{c}\text { Gap } \\
\text { (Digital-Physical) }\end{array}$ \\
\cline { 2 - 4 } & $\%$ & $\%$ & $\%$ \\
\hline By artist & 35.8 & 59.8 & 23.9 \\
\hline By title of work & 0.8 & 13.6 & 12.8 \\
\hline Not organized & 28.3 & 5.4 & -22.9 \\
\hline By genre & 9.2 & 4.9 & -4.3 \\
\hline By preference & 1.7 & 2.7 & 1.1 \\
\hline By frequency of use & 0.8 & 2.2 & 0.3 \\
\hline By record label & 0.0 & 0.5 & -5.8 \\
\hline By format type & 5.8 & 0.0 & -6.6 \\
\hline Others & 17.5 & 10.9 & \\
\hline
\end{tabular}

For both physical and digital collections, organizing music by artist was the most preferred method. For digital collections, in particular, almost $60 \%$ of the respondents selected artist. Approximately one out of four respondents (28.3\%) said they do not organize their physical collection, which is significantly higher than $5.4 \%$ for digital collection. This is most likely due to the fact that many music services/applications automatically organize digital music files in some way, regardless of user input. It is noteworthy that $13.6 \%$ of respondents organized their digital music collection by title of work, yet almost none did so for their physical music collection (0.8\%). We suspect that this is also related to title of work being the default organizational method in certain music services/applications. Considering that this is clearly not a strongly preferred method for organizing users' physical collections, they may find such organization unintuitive. Genre was also a useful organizational criterion for users, and ranked third for both physical and digital collection.

For digital music, 76.5\% of respondents relied on some sort of music management software to manage their collection (Table 14). This supports our idea that default organizational methods in these applications may be affecting the observed distribution. The proportion of respondents who manually manage their music files using directories on their computers was $16.9 \%$. The proportion of people using cloud music services was fairly low (3.3\%), and there was only one respondent who use a home music/media server.

Table 14. Responses to "How do you primarily manage your digital music collection?" (Q10.3)

\begin{tabular}{c|c}
\hline \multirow{1}{*}{} & Valid (N = 183) \\
\cline { 2 - 2 } Using music management software & $\%$ \\
\hline Manually, using directories on your computer's file system & 76.5 \\
\hline Using cloud music services & 16.9 \\
\hline Using a home music/media server & 3.3 \\
\hline Others & 0.5 \\
\hline
\end{tabular}




\section{Emergent Themes and Implications for Designing Music Information Services}

\section{Access model: Streaming and Subscription-Based Services}

Comparison of the results from both surveys shows that Internet radio/music streaming services are becoming increasingly popular. In the 2004 survey, listening to streaming music or online radio $(77.6 \%)$ was the third most popular online activity after reading any kind of music information (86.3\%) and purchasing physical music recordings (81.2\%). In the 2012 survey, it is not only the most popular activity based on the proportion of positive responses (96.6\%), but also the frequency of use as over half of the respondents (54.8\%) said they use the service a few times a week, and approximately one out of three, almost every day (33.2\%). Related to this, the mobile music consumption behavior is also noteworthy: approximately one out of five respondents $(21.1 \%)$ indicated they use music related apps "a few times a week" (7.9\%) to "almost every day" (13.2\%). Streaming music service such as Pandora or Spotify were also an important trigger for music searching; $82.2 \%$ of respondents indicated that they had searched for music heard on streaming services, and approximately one out of four respondents do it a few times a week or more (25.9\%). This trend is not surprising, considering the prevalence of various mobile devices like tablets and smartphones. The storage limitation on these devices can be one explanation for why users prefer these kinds of services rather than carrying their own music collection. Respondents' answers to the open-ended question asking about their favorite music-related websites/applications in the survey (Q3) further support this:

\section{"I like them because I can still listen to music without cluttering up my phone or work computer with extra files."}

"I also use things like spotify and pandora to listen to music that I don't necessarily want to own but have a hankering for now and again."

As users continue to collect and store photos, videos, games, documents, and apps in addition to music in the same device, they will often find the storage space limited (Lee \& Waterman, 2012). This is one of the reasons cloud-based services may appeal to users. Building a music collection was still an important reason for music information seeking as evidenced by statistics related to music purchase behaviors, although the shift to digital formats is evident. Overall, the data seem to indicate that the notion and use of personal collection may be shifting; for many respondents, their personal collections do not always seem to be the primary source for listening to music. Although people still develop their music collections, they certainly do it less frequently, and for everyday music listening or specific known-item searches they appear to rely on services like Pandora, Spotify, or YouTube. This may be related to the difficulty of access to, limited variety of, or inability to discover new artists in personal music collections. This is evidenced in some responses given to the open-ended question (Q3) asking about which music services they prefer and why:

"(YouTube) gives an incredibly large choice of uploaded music to listen to (once again, including some specialized and rare items I wouldn't be able to find in my local library)." 
“...element of serendipity, discovery of new music (is why I like Pandora).”

Managing digital music collections can also be challenging as people switch to new computers, phones, and other devices frequently, sometimes without fully copying all the content from old to new devices. Although the number of respondents who currently use cloud-based services is still small, we expect that the popularity of these services will significantly increase in the next few years. This may have a direct impact on how much of the personal collection people will use for listening.

\section{Social Aspect of Music Experience: Collaborative Music Seeking, Listening, and Sharing}

The survey data confirmed that there is a strong social component to people's experience of and interaction with music, and music services that successfully incorporate such social features are well received. Evidence is found with regard to multiple types of user behaviors including music listening, searching, and seeking recommendations. Seventy-five percent of respondents indicated that they searched for music that they heard at their friend's or acquaintance's place with approximately one out of three $(34.0 \%)$ responding they do it more than two or three times a week. Over half of the respondents (53.2\%) also indicated that they visit either a friend's or acquaintance's place when they search for music. Approximately four out of five respondents (82.8\%) said they ask friends or family members for help when they search for music and about three out of five respondents $(60.0 \%)$ answered they ask people on their social network sites. Approximately half of the respondents (54.2\%) said they are likely to seek review/rating information and three out of four respondents $(77.3 \%)$, recommendations from others. The proportions of respondents selecting these different options also tended to increase in the new survey. In addition, several answers to the open-ended question (Q3) also support the importance of the social aspect of music listening, illustrating users' desire to know what their friends listen to and also share their music:

"I also make extensive use of Last.fm to track my listening habits over time, and keep up to date with what my friends are listening to."

“[I like] to introduce family member/friend to music I like \& vice versa.”

"Music posted on social networking sites (especially Google+), posted or shared by friends there, I listen to what they recommend and look for more if I like it."

"I love turntable.fm and Pandora the most-turntable because it lets me share the music I like with friends who haven't heard it before."

Altogether, the data suggest that music listening and enjoyment are not just personal matters that happen in isolation but also happen as a "public and shared process" (Lee \& Downie, 2004). People tend to rely on each other for their music search and browse activities, and even though recommender systems are extremely popular, people still seem to prefer getting recommendations from other people-this may be related to several factors such as trust in the ability to receive good recommendations, privacy concerns, compatibility issues for apps/devices, convenience, and more. In fact, in the follow-up study on people's use of music services, a number of interviewees exhibited their distrust in machines to truly understand their music tastes, and some respondents were even offended 
that machines are telling them how they should live their lives (Lee \& Price, in press). Regarding privacy, there was a mix of responses expressing varying degrees of concerns (Lee \& Price, in press):

\begin{abstract}
"I already feel like a lot of places have too much information about me...I wouldn't want to give a system more information about me even if it would provide a perfect playlist, because I still want to have control of that...I's creepy. I like having some degree of control and privacy." (User 13)
\end{abstract}

"I don't use the Genius thing at all, it scares me. I don't want it to take over and know what I have. I don't share what I have with Apple." (User 19)

\begin{abstract}
"Music choices are so personal...it's very difficult [for a service to recommend music]. These [recommendations] are weird. I think this Discover page came up on my laptop recently, and they were telling me 'It's been a while since you've listened to this [song]', and that was a little weird! It's like, I can figure out what I want to listen to, I don't need your help, Spotify!" (User 8)
\end{abstract}

"I'm split between 'that's really cool' and 'that's kind of creepy.' If I had the option to control [the information it has about me] then that might be something I accept...I don't want the system to make assumptions, but at the same time I think that it's really neat." (User 30)

"When you download the software, the automatic preference is that Spotify will open every time you turn on your computer. I don't like that. The first time I ever downloaded Spotify, that was the reason I didn't use it [right away]. I felt like it was hijacking my computer. I get really frustrated with things that feel like they're hijacking my computer." (User 1)

Adding more human-like, personal touches to recommendations may appeal to these types of users. In addition to automatically generated playlists, providing ones that are manually created or endorsed by staff and/or music experts can potentially help (e.g., as in Songza ${ }^{11}$ which was recently acquired by Google ${ }^{12}$ ). Allowing users to easily save and share their own playlists can also be desirable, especially if it is coupled with an ability to easily set different access permissions to address users' privacy concerns.

\title{
"Visual" Music Experience and Integration with Other Media
}

Another strong pattern that emerged from the survey data is the popularity of musicrelated multimedia. This is supported by the fact that $95.1 \%$ of respondents sought online music multimedia with $27.5 \%$ doing so almost every day, and $54.9 \%$ additionally sought music multimedia in other formats. As previously mentioned, YouTube was also ranked the second most preferred music service by respondents. In addition to the excellent coverage of music and not being restricted to particular software or hardware, one of the main reasons YouTube was so popular among respondents was because they can see music videos or lyrics as they were listening to music (Lee \& Waterman, 2012). Sharing and promoting music has also become one of the primary reasons for people using YouTube, evidenced by the numerous music videos available on YouTube, as well as the fact that of the top 30 most-watched videos on YouTube of all time, 29 are music videos ${ }^{13}$. 
Although "album artwork/cover" is also visual information related to music, the fact that it was less attractive to users (53.3\% of negative responses) may be related to the shift in the way users commonly obtain and listen to music, from physical to digital. For digital music, users typically obtain an individual music file rather than the whole album, and therefore album artwork/cover would be naturally less relevant to them. It is also noteworthy that this category still showed the most significant increase in the proportion of positive responses in the new survey.

Due to the dominance of YouTube, offering the same feature for sharing video content may not be sufficient to attract users to switch to a different service. However, providing direct links to official music videos and other music-related video content on YouTube may add value as an index, as searching for particular videos clips (especially the official version of music video) can be challenging on YouTube, where numerous copies of content coexist.

\section{From Metadata to Ontology: Contextual Information and Relationships Among Artists/Music}

The fact that substantial proportions of respondents answered positively with regard to their information need such as "information on musical genre/style (58.5\%)," "influences to/from other artist(s) (52.9\%)," and "music background information (41.9\%)," and that the proportions increased in the new survey show users' desire to learn more about the background and context of music beyond simply listening to music. In addition, some responses given as "other" reasons users seek music or music information (Q8.1) show the depth of users' music appreciation and as well as their desire to use music as a vehicle for learning about different cultures and philosophies.

"To learn more about cultural groups or eras. I've sought out music from specific cultures to learn about them, and from specific eras (such as the 1990s) because I felt curious about why I didn't remember very much music from that time." "To learn more about different cultures, especially those I might be working with in my research."

"(To) ponder philosophies, issues, ideas, emotions treated in musical lyrics and melodies."

A number of respondents also stated that they preferred information resources such as Wikipedia because "it has the most (information) and most interesting information on artists and albums," and it is great for obtaining a variety of background information such as "artist/group discographies, also historical information, information on particular musical instruments, world music, etc." (Q3). This supports the idea that representing the whole music domain including the relationships among artists, musical works, subjects or genres of music, etc., will be essential to meet this type of user need. We envision that research on music ontology based on the Semantic Web and Linked Data approach (e.g., Raimond, Abdallah, Sandler, \& Giasson, 2007; Raimond, Sutton, \& Sandler, 2009) will become significant for successful future music applications and services.

\section{Conclusion and Future Work}

Comparing the survey results from 2004 and 2012 did reveal several changes in the information needs and behaviors of general music users. Respondents in the new survey 
relied more on streaming services and online social media, actively sought music multimedia, valued serendipitous discovery of music, and were more disconnected from physicality both in terms of the kind of music they purchased and where they went to seek music information. New issues such as privacy concerns, compatibility among devices, and limitation of storage also emerged. Although we focused on people's music information needs and behaviors, a number of these themes may have direct relevance to how we seek, organize, and consume other popular cultural objects such as games or videos. In fact, the shift to streaming and subscription-based model has unquestionably happened for movies (e.g., Netflix ${ }^{14}$ streaming service), and a move from physical to digital formats is currently happening for video games (e.g., Steam, PlayStation Network, Xbox Live). The rise of YouTube and Twitch ${ }^{15}$ for sharing video game playthroughs, trailers, commentaries, etc. is also notable. Our user data also show similar patterns, with an indication of the increasing popularity of streaming and digital music as well as the need for visual music experience.

Two follow-up studies are currently being conducted: (a) a study investigating how people use and evaluate various commercial music services through interviews and think-aloud sessions, and (b) a study specifically exploring how people use cloud music services. For future work, we also plan to show how the information needs and behaviors of music experts (users with music-related professions) changed over time. In addition, we will compare the differences between music experts and general music users.

\section{Acknowledgments}

We would like to thank Nichole M. Waterman, Ben Farabelli, and M. Cameron Jones for their help in setting up the online survey, collecting, and processing the survey data, and Rachel Price for sharing the interview transcripts. We also extend special thanks to everyone who participated in the survey, and helped recruit participants.

\section{References}

Bainbridge, D., Cunningham, S.J., \& Downie, J.S. (2003). How people describe their music information needs: A grounded theory analysis of music queries. In Proceedings of the Fourth International Conference on Music Information Retrieval (pp. 221-222). Baltimore, Maryland: ISMIR.

Barrington, L., Oda, R., \& Lanckriet, G. (2009). Smarter than Genius? Human evaluation of music recommender systems. In Proceedings of the 10th International Society for Music Information Retrieval Conference (pp. 357-362). Kobe, Japan: ISMIR.

Barthet, M., \& Dixon, S. (2011). Ethnographic observations of musicologists at the British library: Implications for music information retrieval. In Proceedings of the 12th International Society for Music Information Retrieval Conference (pp. 353-358). Miami, Florida: ISMIR.

Brenner, J. (2013). Pew Internet: Mobile. Retrieved from http://pewinternet.org/Commentary/2012/February/Pew-Internet-Mobile.aspx

Brinegar, J., \& Capra, R. (2011). Managing music across multiple devices and computers. In Proceedings of the iConference 2011 (pp. 489-495). Seattle, WA: ACM. 
comScore. (2013). comScore reports May 2013 U.S. smartphone subscriber market share. Retrieved from: http://www.comscore.com/Insights/Press-Releases/2013/6/comScoreReports-May-2013-US-Smartphone-Subscriber-Market-Share

Cunningham, S.J. (2003). User studies: a first step in designing an MIR testbed. In The MIR/MDL Evaluation Project White Paper Collection (3rd ed., pp. 19-21). Champaign, IL: GSLIS.

Cunningham, S. J., Reeves, N., \& Britland, M. (2003). An ethnographic study of music information seeking: Implications for the design of a music digital library. In Proceedings of the Third ACM/IEEE-CS Joint Conference on Digital Libraries (pp. 5-16). Houston, TX: ACM.

Cunningham, S.J., Jones, M., \& Jones, S. (2004). Organizing digital music for use: An examination of personal music collections. In Proceedings of the Fifth International Conference on Music Information Retrieval (pp. 206-212). Barcelona, Spain: ISMIR.

Cunningham, S.J., Bainbridge, D., \& McKay, D. (2007). Finding new music: A diary study of everyday encounter with novel songs. In Proceedings of the Eight International Conference on Music Information Retrieval (pp. 83-88). Vienna, Austria: ISMIR.

Dervin, B. (1983). An overview of sense-making research: Concepts, methods and results to date. International Communications Association Annual Meeting, Dallas, Texas. Retrieved from https://www.ideals.illinois.edu/bitstream/handle/2142/2281/Dervin83a.htm

Downie, J.S. (1994). The musifind musical information retrieval project, phase II: User assessment survey. In Proceedings of the 22nd Annual Conference of the Canadian Association for Information Science (pp. 149-166). Toronto, Canada: CAIS.

Downie, J.S., Byrd, D., \& Crawford, T. (2009). Ten years of ISMIR: Reflections on challenges and opportunities. In Proceedings of the 10th International Society for Music Information Retrieval Conference (pp. 13-18). Kobe, Japan: ISMIR.

Ellis, D. (1989). A behavioural approach to information retrieval design. Journal of Documentation, 45(3), 171-212.

Ellis, D.P.W., Whitman, B., Berenzweig, A., \& Lawrence, S. (2002). The quest for ground truth in musical artist similarity. In Proceedings of the Third International Conference on Music Information Retrieval (pp. 170-177). Paris, France: ISMIR.

Futrelle, J., \& Downie, J. S. (2002). Interdisciplinary communities and research issues in music information retrieval. In Proceedings of the Third International Conference on Music Information Retrieval (pp. 215-221). Paris, France: ISMIR.

Inskip, C., Butterworth, R., \& MacFarlane, A. (2008). A study of the information needs of the users of a folk music library and the implications for the design of a digital library system. Information Processing \& Management, 44(2), 647-662.

Itoh, M. (2000). Subject search for music: Quantitative analysis of access point selection. In Proceedings of the First Annual International Symposium on Music Information Retrieval. Plymouth, Massachusetts: ISMIR. 
Krikelas, J. (1983). Information-seeking behavior: Patterns and concepts. Drexel Library Quarterly, 19(2), 5-20.

Kuhlthau, C.C. (1993). A principle of uncertainty for information seeking. Journal of Documentation, 49(4), 339-355.

Lai, K., \& Chan, K. (2010). Do you know your music users' needs? A library user survey that helps enhance a user-centered music collection. Journal of Academic Librarianship, 31(1), 63-69.

Laplante, A., \& Downie, J.S. (2006). Everyday life music information-seeking behaviour of young adults. In Proceedings of the Seventh International Conference on Music Information Retrieval (pp. 381-382). Victoria, BC: ISMIR.

Leckie, G.J., Pettigrew, K.E., \& Sylvain, C. (1996). Modeling the information seeking of professionals: A general model derived from research on engineers, health care professionals and lawyers. Library Quarterly, 66(2), 161-193.

Lee, J.H. (2010a). Analysis of user needs and information features in natural language queries seeking music information. Journal of the American Society for Information Science and Technology, 61(5), 1025-1045.

Lee, J.H. (2010b). Crowdsourcing music similarity judgments using Mechanical Turk. In Proceedings of the 11th International Society for Music Information Retrieval Conference (pp. 57-62). Utrecht, Netherlands: ISMIR.

Lee, J. H. (2011). How similar is too similar?: Exploring users' perceptions of similarity in playlist evaluation. In Proceedings of the International Society for Music Information Retrieval Conference (pp. 109-114). Miami, Florida: ISMIR.

Lee, J.H., \& Cunningham, S.J. (2013). Toward an understanding of the history and impact of user studies in music information retrieval. Journal of Intelligent Information Systems, 41(3), 499-521.

Lee, J.H., \& Downie, J.S. (2004). Survey of music information needs, uses, and seeking behaviours: Preliminary findings. In Proceedings of the 5th International Conference on Music Information Retrieval (pp. 441-446). Barcelona, Spain: ISMIR.

Lee, J. H. \& Price, R. (in press). User experience with commercial music services: an empirical exploration. Journal of the Association for Information Science and Technology.

Lee, J.H., Hill, T., \& Work, L. (2012). What does music mood mean for real users? In Proceedings of the 2012 iConference (pp. 112-119). Toronto, Canada: ACM.

Lee, J. H., \& Waterman, N, M. (2012). Understanding user requirements for music information services. In Proceedings of the 13th International Society for Music Information Retrieval Conference (pp. 253-258). Porto, Portugal: ISMIR. 
Lee, Y.J., \& Moon, S.B. (2006). User study on information searching behaviors for designing user-centered query interface content-based music information retrieval system. Journal of the Korean Society for Information Management, 23(3), 5-19.

Lesaffre, M., Voogdt, L.D., Leman, M., Baets, B.D., Meyer, H.D., \& Martens, J.P. (2008). How potential users of music search and retrieval systems describe the semantic quality of music. Journal of American Society for Information Science and Technology, 59(5), 695-707.

Maguire, M., Motson, D.E., Wilson, G., \& Wolfe, J. (2005). Searching for Nirvana: Cataloging and the digital collection at the experience music project. Journal of Internet Cataloging, $7(1), 9-31$.

Mandel, M., Eck, D., \& Bengio, Y. (2010). Learning tags that vary within a song. In Proceedings of the 11th International Society for Music Information Retrieval Conference (pp. 399-404). Utrecht, Netherlands: ISMIR.

McHugh, M.L. (2013). The Chi-square test of independence. Biochemia Medica, 23(2), 143149.

McPherson, J.R., \& Bainbridge, D. (2001). Usage of the MELDEX digital music library. In Proceedings of the Second Annual International Symposium on Music Information Retrieval (pp. 19-20). Bloomington, Indiana: ISMIR.

Nielsen. (2013). The Nielsen company \& Billboard's 2012 music industry report. Retrieved from http://www.businesswire.com/news/home/20130104005149/en/NielsenCompany-Billboard\%E2\%80\%99s-2012-Music-Industry-Report

Pauws, S., \& Eggen, B. (2002). PATS: Realization and user evaluation of an automatic playlist generator. In Proceedings of the Third International Conference on Music Information Retrieval (pp. 222-230). Paris, France: ISMIR.

Raimond, Y., Abdallah, S.A., Sandler, M., \& Giasson, F. (2007). The music ontology. In Proceedings of the Eight International Conference on Music Information Retrieval (pp. 417422). Vienna, Austria: ISMIR.

Raimond, Y., Sutton, C., \& Sandler, M. (2009). Interlinking music-related data on the Web. IEEE MultiMedia, 16(2), 52-63.

Savolainen, R. (1995). Everyday life information seeking: Approaching information seeking in the context of "way of life." Library \& Information Science Research, 17(3), 259-294.

Sordo, M., Celma, O., Blech, M., \& Guaus, E. (2008). The quest for musical genres: Do the experts and the wisdom of crowds agree? In Proceedings of the 9th International Conference on Music Information Retrieval (pp. 255-260). Philadelphia, USA: ISMIR.

Taheri-Panah, S., \& MacFarlane, A. (2004). Music information retrieval systems: Why do individuals use them and what are their needs? In Proceedings of the 5th International Conference on Music Information Retrieval (pp. 455-460). Barcelona, Spain: ISMIR. 
Urbano, J., Morato, J., Marrero, M., \& Martin, D. (2010). Crowdsourcing preference judgments for evaluation of music similarity tasks. In Proceedings of the SIGIR 2010 Workshop on Crowdsourcing for Search Evaluation (pp. 9-16). Geneva, Switzerland: ACM.

Weigl, D.M., \& Guastavino, C. (2011). User studies in the music information retrieval literature. In Proceedings of the 12th International Society for Music Information Retrieval Conference (pp. 335-340). Miami, Florida: ISMIR.

Wilson, T.D. (1981). On user studies and information needs. Journal of Documentation, $37(1), 3-15$.

Wilson, T.D. (1997). Information behaviour: an interdisciplinary perspective. Information Processing \& Management, 33(4), 551-572.

\section{APPENDIX: SURVEY QUESTIONNAIRE}

Note: Newly added questions/response options in the 2012 survey are marked with a plus (+) sign. Response options that were revised in 2012 are marked with an asterisk $\left(^{*}\right)$.

Q1. What kind of music are you interested in? Choose up to 5 music genres you listen to frequently from the list below and rank them in order of preference.
1) Alternative
2) Blues
3) Children's
4) Classical
5) Country
6) Dance
7) Easy Listening
8) Electronica
9) Folk
10) Gospel
11) Hard Rock/Heavy Metal
12) Hip Hop/Rap
13) Jazz
14) Latin
15) New Age
16) Oldies
17) Pop
18) Reggae
19) R\&B/Soul
20) Rock
21) Opera/Vocal
22) World
23) Other

1.1. If "Other," what music genre(s)?

Q2. Do you use the Internet to search for music or music information? 

1) Yes
2) No

Q2.1. How often do you do the following activities ONLINE? Please choose the appropriate response for each item.

Visit online music stores
1) Almost every day
2) A few times a week
3) About once a week
4) 2 or 3 times a month
5) Once a month or less
6) Never

[same response options repeated]

Purchase music recordings (e.g., CDs, vinyl records, tapes)

Purchase and download electronic/digital music files

Download free electronic/digital music files

Listen to streaming music/online radio

Use cloud music services

Download sheet music/scores

Read any kind of music information (e.g., news, articles, reviews)

Visit online music forums, Webboards, chatrooms, or communities

Read/subscribe to music listservs/mailing lists

Play music-related video games (e.g., Rock Band, Guitar Hero)+

Use music apps or music-themed apps on your mobile phone (e.g., Shazam, Google Listen)+

Q3. What are your favorite music-related websites or apps? What do you like about them?

Q4. How often do you search/browse for the following items (both online and offline)?

Music recordings (e.g., CDs, vinyl records, tapes)
1) Almost every day
2) A few times a week
3) About once a week
4) 2 or 3 times a month
5) Once a month or less
6) Never

[same response options repeated]

Electronic/digital music files (e.g., mp3s, midi)

Online music multimedia (e.g., YouTube videos, music videos on Yahoo! Music)+

Music multimedia in other formats (e.g., Blue-ray, DVD, VHS)

Music magazines 
Music/entertainment news

Music-related software

Music-related video games

Sheet music/scores

Books on music

Academic music journal articles

Q4.1. Do you search for any other music-related item not listed above? If so, what?

Q5. How often do you ask the following people/services for help when you search for music or music information?

Friends/family members

1) Almost every day

2) A few times a week

3) About once a week

4) 2 or 3 times a month

5) Once a month or less

6) Never

[same response options repeated]

Online music community/forum members

People on your social network websites (e.g., Facebook, Google Plus)

Musicians

Music librarians

Record store staff

Teachers/music instructors

Music identification services/software (e.g., Shazam)+

Q5.1. Do you ask anyone not listed above for help? If so, who?

Q6. How often do you go to the following physical places to search for music or music information?

Friend's/acquaintance's home

1) Almost every day

2) A few times a week

3) About once a week

4) 2 or 3 times a month

5) Once a month or less

6) Never

[same response options repeated]

Record store

Library 
Academic institution (e.g., school, university)

Q6.1. Do you go to any other places for music information not listed above? If so, where?

Q7. How often do you search for music heard from the following sources?

Radio show

1) Almost every day

2) A few times a week

3) About once a week

4) 2 or 3 times a month

5) Once a month or less

6) Never

[same response options repeated]

Online streaming music services (e.g., Pandora, Spotify)+

Advertisement/commercial

TV show/movie/animation

Online video clip (e.g., YouTube)+

Music-related video game+

Friend's/acquaintance's home

Concert/recital

Public place (e.g., café, store, bar, dance club, office)

Special occasion (e.g., wedding, party, presentation, event)

Cultural event ${ }^{16}$

Q7.1. Do you search for music heard from any other source? If so, what?

Q.8. How often do you seek music or music information for the following reasons?

To listen for entertainment

1) Almost every day

2) A few times a week

3) About once a week

4) 2 or 3 times a month

5) Once a month or less

6) Never

[same response options repeated]

To identify/verify musical work, artist, lyrics, etc.

To learn about items before purchase

To build your music collection

To learn more about music

To learn more about music artists 
To learn more about musical instruments

To listen for work/study purpose

For use in teaching/instruction

For use in academic research in music-related fields

To sing or play a musical instrument for entertainment (e.g., karaoke, family sing-along)

To sing or play a musical instrument professionally

To use for electronic gadgets (e.g., cellphone ringtone, computer sound effect)

To use in video clips or slideshows+

To use for special occasions (e.g., weddings, parties, presentations, events)

To play in certain places (e.g., cafes, stores, bars, dance clubs, offices)

Q8.1. Do you seek music or music information for any reason not listed above? If so, why?

Q9. Do you own a physical music collection?+

1) Yes

2) No

Q9.1. How big is your physical music collection (e.g., CD, vinyl records, tapes)? Please estimate the number of recordings.+

Q9.2. How is your physical music collection organized?+

1) By genre

2) By artist

3) By album title

4) By record label

5) By frequency of use

6) By preference

7) By format type

8) Not organized

9) Other

Q10. Do you own a digital music collection?+

1) Yes

2) No

Q10.1. How big is your digital music collection (e.g., mp3s, midi)? Please estimate the number of files and the amount of disk space that your music collection requires.+

Number of files

Size of disk space in gigabytes

Q10.2. How is your digital music collection primarily organized?+

1) By genre

2) By artist

3) By album title

4) By record label 
5) By frequency of use

6) By preference

7) By format/file type

8) Not organized

9) Other

Q10.3. How do you primarily manage your digital music collection?+

1) Manually, using directories on your computer's file system

2) Using music management software (e.g., iTunes)

3) Using cloud music series (e.g., Google Music, Amazon's Your Media Library)

4) Using a home music/media server (e.g., Subsonic, Wowza)

Q11. Which of the following best describes you? Please check all that apply.

1) Avid listener: I listen to music regularly

2) Casual listener: I listen to music occasionally

3) Avid performer: I play musical instrument(s) or sing regularly

4) Casual performer: I play musical instrument(s) or sing occasionally

5) Musically passionate: I really like music: it's a big part of my life

6) Musically curious: I enjoy music, but I'm not too crazy about it

7) Other

Q12. How well can you read sheet music?

1) Very well: I don't have any problem

2) Fairly well: I might get stuck once in a while but I'll figure it out

3) OK: I can, but with a lot of time and effort

4) Not very well: Maybe just a few notes

5) Not at all: All I see are dots and lines

Q13. How well can you sing?

1) Very well: I can be the next American idol!

2) Fairly well: I can be a star at karaoke

3) OK: I wouldn't quit my day job

4) Not very well: My friends might leave the room

5) Not at all: I won't sing even when I'm alone in the shower

Q14. Can you play a musical instrument?

1) Yes

2) No

Q14.1. What instrument(s) can you play? Choose ALL that apply.

1) Drum family (membranophone) (e.g., timpani, snare drum, bongos, table)

2) Stringed instrument (chordophone) (e.g., violin, piano, guitar, harp)

3) Wind instrument (aerophone) (e.g., clarinet, trumpet, harmonica, accordion, pipe organ) 
4) Percussion instrument (idiophone) (e.g., marimba, maracas, musical saw, mbira)

5) Electronic instrument (electrophone) (e.g., synthesizer, Theremin, turntables, mellotron)

Q14.2. After you've heard a melody, could you play it on a piano?
1) Yes
2) With difficulty
3) No

Q15. When you search for music or browse a music collection, how likely are you to use the following search/browse options if they were available to you?

By title of work(s)
1) Very likely
2) Somewhat likely
3) Not very likely
4) Not at all likely
5) Don't know

[same response options repeated]

By publisher/record label

By performer

By creator (e.g., composer, songwriter)

By release/composition date

By time period

By instrument(s)

By vocal range/genders (e.g., high/low, male/female)

By some words of the lyrics

By theme/main idea/storyline of music (e.g., money, love)

By place/event where music was heard

By language

By popularity

By country

By singing or humming a melody

By music identification service (e.g., Shazam)+

By tempo (e.g., fast, slow)

By using keyboard input

By mood/emotional state induced

By occasions to use (e.g., wedding, party)

By associated usage (e.g., movie, advertisement, TV show, video game)

By similar music

By similar artist

By specific version

By purchase patterns (e.g., people who bought this title also bought...)

By recommendations from other people

By recommendations from recommender systems (e.g., Apple Genius, Pandora)+ 
Q16. How likely are you to seek the following music information?

Title of work(s)
1) Very likely
2) Somewhat likely
3) Not very likely
4) Not at all likely
5) Don't know

[same response options repeated]

Music background information (history, theory, etc.)

Artist information

Influences to/from other artist(s)

Information on musical genre/style

Album artwork/cover

Track listing

Lyrics

Release date

Record label

Price of item

Links to related website information

Sample tracks for listening

Information on different version(s) of work(s)

Review/rating by other people

Q17. On what device(s) do you listen to music? Choose ALL that apply.+
1) Computer
2) Stereo
3) Phone
4) iPod/mp3 player
5) iPad/tablet PC
6) E-reader (e.g., Kindle, Nook)
7) Other:

Q18. Do you have any comments related to the questions on this survey? Any other information you would like to share?+

Q19. What is your gender?
1) Male
2) Female
3) Other+:

Q20. How old are you?

Q21. What is your nationality? 
Q22. Which of the following best describes you?

1) White or Caucasian

2) Asian or Pacific Islander

3) Black or African American

4) Native American or First Nations

5) Other:

Q23. Are you of Hispanic or Latino origin or descent?
1) Yes
2) No

Q24. Do you have a music-related job/profession or hobby?
1) Yes
2) No

Q24.1. Which of the following best describes you? Please check ALL that apply.
1) Professional musician
2) Amateur musician
3) Composer
4) Producer
5) Music-related performer (e.g., DJ, dancer)
6) Musicologist
7) Music-related researcher
8) Music student (college or university level)
9) Music librarian
10) Music salesperson

11) Other:

\footnotetext{
${ }^{1}$ Spotify is a commercial online music streaming and recommendation service that provides users access to millions of music tracks (https://www.spotify.com/us/).

2 Pandora (Internet Radio) is a music streaming and recommendation service where users can create personalized radio stations. (http://www.pandora.com/).

${ }^{3}$ Last.fm is an online music discovery service that provides personalized recommendations based on what users listen to (http://www.last.fm/).

4 "Positive" category presents the sum of responses that selected "almost every day" to "once a month or less," and "Negative" category represents the number of responses that selected "never." The same categorization is used in all the tables presenting results of survey questions asking about the frequency of engaging in particular activities.

${ }^{5}$ In the new survey, this category was listed as "Music multimedia in other formats (e.g., Blue-ray, DVD, VHS) in order to distinguish it from "Online music multimedia."

${ }^{6}$ YouTube is a website where people can discover, watch, and share videos (https://www.youtube.com/).

${ }^{7}$ Yahoo! Music is a web portal owned by Yahoo which provides services including Internet radio, music videos, and music-related news and information (https://music.yahoo.com/).
} 
${ }^{8}$ In the old survey, this reason was phrased as "to sing or play a musical instrument." In the new survey, it was separated to two reasons asking about singing or playing an instrument "for entertainment" or "professionally." For comparison, the responses of these two reasons in the new survey were combined. The responses that were positive for either one of the two reasons were counted as positive and the rest, negative.

9 "Positive" category presents the sum of responses that selected "very likely" and "somewhat likely." "Negative" category represents the sum of responses that selected "not very likely" and "not at all likely." The same categorization is used in all the tables presenting results of survey questions asking about the likelihood of engaging in particular activities.

${ }^{10} \mathrm{~N}$ is the total number of responses where the respondent specified the reasons for liking particular music services in each survey.

${ }^{11}$ Songza is an online music streaming and recommendation service. The recommendations are made by music experts, and it offers selections of music for particular time of day, mood, or activity (http://songza.com/).

12 https://plus.google.com/+GooglePlay/posts/9FotaTDAw34

13 YouTube chart (http://en.videotrine.com/all/youtube/all-time), as of January 20, 2014.

${ }^{14}$ Netflix is a subscription-based digital distribution service which also provides on-demand Internet streaming media (https://www.netflix.com/?locale=en-US).

15 Twitch is a live streaming video platform and community for gamers (http://www.twitch.tv/).

${ }^{16}$ After discussion, this option was removed in the newer survey as it may be unclear to the respondents what the difference between special occasions and cultural events is. 